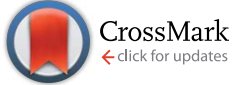

Cite this: RSC Adv., 2016, 6, 80145
Received 25th July 2016

Accepted 13th August 2016

DOI: $10.1039 / c 6 r a 18842 \mathrm{~g}$

www.rsc.org/advances

\section{Insight into the acidic group-induced nitration mechanism of 2-methyl-4,6-dihydroxypyrimidine (MDP) with nitronium $\dagger$}

\author{
Kuan Wang, ${ }^{a}$ Jian-Gang Chen, ${ }^{\text {a }}$ Bozhou Wang, ${ }^{\mathrm{b}}$ Yueping Ji, ${ }^{\mathrm{b}}$ Fengyi Liu, ${ }^{\mathrm{a}}$ \\ Zhao-Tie Liu, ${ }^{* a}$ Wenliang Wang, ${ }^{a}$ Zhong-Wen Liu, ${ }^{a}$ Zhengping Hao ${ }^{\text {ac }}$ and Jian Lu*b
}

\section{Introduction}

Energetic materials are of especially great importance to economic and social development, and play an irreplaceable role in military affairs and national security. However, there exists a severe defect in the current extensively employed energetic materials: they are too sensitive to physical conditions

\footnotetext{
${ }^{a}$ Key Laboratory of Applied Surface and Colloid Chemistry (MOE) and School of Chemistry \& Chemical Engineering, Shaanxi Normal University, Xi'an, 710119, China. E-mail: jgchen@snnu.edu.cn; ztliu@snnu.edu.cn; Fax: +86-29-81530803; +86-29-81530802; Tel: +86-29-81530803; +86-29-81530802

${ }^{b}$ Department of Catalytic Technology, Institute of Xi'an Modern Chemistry, Xi'an, 710065, China. E-mail: lujian204@263.net; Tel: +86-29-88291213

'Research Centre for Eco-Environmental Science, Chinese Academy of Sciences, Beijing, 100085, China

$\dagger$ Electronic supplementary information (ESI) available: The calculated Mulliken atomic charges of MDP and the relevant intermediate. Schematic energy diagram of the direct nitration of MDP with $\mathrm{NO}_{2}{ }^{+}$. Schematic energy diagram of the $\mathrm{HSO}_{4}{ }^{-}$-induced nitration of MDP with $\mathrm{NO}_{2}{ }^{+}$. Schematic energy diagram of the direct $\mathrm{H}$-transfer of mono-nitro substitution product. Schematic energy diagram of the direct $\mathrm{H}$-transfer of di-nitro substitution product. Schematic energy diagram of the trans- $\mathrm{HSO}_{4}{ }^{-}$-induced nitration in the second nitration step in path C. Free energies and active free energies for the nitration of MDP with $\mathrm{NO}_{2}{ }^{+}$in the gas, formamide and dimethylsulfoxide phases. Optimized geometries of species for the rate-limiting step in paths A-C. See DOI: $10.1039 / \mathrm{c} 6 \mathrm{ra} 18842 \mathrm{~g}$
}

(heat, impact and friction, etc.). Such a defect often leads to grievous casualties and severe accidents during production, transportation, storage and application, and has thus spurred numerous attempts to develop promising candidates for insensitive energetic materials to replace the traditional ones. The discovery of 1,1-diamino-2,2-dinitroethylene (FOX-7/ DADNE) may be one of the most exciting events in the research of energetic materials. ${ }^{1}$ Owing to its superior performances of high energy density, high explosive and most importantly, lower sensitivity towards impact and friction, FOX7 is increasingly accepted as a kind of new insensitive energetic materials. Therefore, in recent years much attention has been paid to investigating FOX-7 from various aspects, including the synthetic method, ${ }^{2-6}$ molecular/crystal structure, ${ }^{1,7-11}$ thermodynamic property, ${ }^{12-15}$ explosive performance, ${ }^{16,17}$ thermal decomposition $^{18}$ and other performances/properties ${ }^{19-21}$ in recent years. However, so far quite few references can be found focusing on the synthesis mechanism of FOX-7. The absence of such significant details severely hinders the further research and application of FOX-7.

Based on the currently available publications, it is found that the most popular strategy on the preparation of FOX-7 is started with the nitration of 2-methyl-4,6-dihydroxypyrimidine (MDP) in nitric-sulfuric acids, followed by the hydrolysis of the nitration product of 2-dinitromethylene-5,5-dinitropyrimidine-4,6- 
dione (N-MP). ${ }^{3-5}$ The typical preparation strategy of FOX-7 is shown in Scheme 1.

Most nitration reactions to prepare energetic materials are found to correspond to electrophilic substitution mechanism, particularly in the nitration of the aromatics. ${ }^{22-26}$ Such mechanism was primarily verified by Esteves et al. via both simulation and experiment. ${ }^{23}$ Moreover, the nitration of benzene with $\mathrm{NO}_{2}{ }^{+}$ in the gas phase was found to follow a polar mechanism ${ }^{24}$ in the last stage of the electrophilic substitution, providing a further understanding to the nitration details. While in view that the actual nitration mostly occurred in nitric-sulfuric acids (in which the sulfuric acid may (partly) act as the solvent), the impacts of the reaction medium on the nitration, namely the solvent effect should be considered. Koleva et $a .^{25}$ found that formamide may be used as a model solvent for the nitration in nitric-sulfuric acids because the dielectric constant of formamide $(\varepsilon \approx 108.94)$ is quite close to that of sulfuric acid $(\varepsilon \approx$ 100). A less polar medium of dimethylsulfoxide $(\varepsilon=46.8)$ was also employed as a model because of its similar structure to sulfuric acid. Interestingly, the obtained quite analogous potential energy surfaces in two model solvents indicated that the polarity of the medium may have slight/little impact on the nitration of benzene in mixed acid. Namely, the solvent effect in the nitration system may not be as noticeable as was expected. Such inference/assumption should be verified in the present work.

Since four nitro groups $\left(-\mathrm{NO}_{2}\right)$ should be prerequisitly introduced to MDP during the formation of N-MP, the capture, separation and detection of the possible intermediates during the nitration process is hardly accomplished, resulting that the experimental investigation of the nitration details is considerably challenging. To the best of our knowledge, the detailed nitration mechanism of MDP has never been reported so far. As compared with the incompetency of experiential ways, the theoretical calculation/simulation, especially the DFT-B3LYP/6$311 \mathrm{G}(\mathrm{d}, \mathrm{p})$ seems to be a versatile/promising method to the mechanism exploration of nitration systems from others ${ }^{27-29}$ and ours. ${ }^{30,31}$ Herein, the DFT-B3LYP/6-311G(d,p) method is employed aiming at the understanding of the nitration mechanism in the present work. While the following hydrolysis details of N-MP to form FOX-7 have also been investigated, and will be presented in another work. ${ }^{32}$

It is suggested that $\mathrm{NO}_{2}^{+}$may actually act as the nitration regent when the nitration reactions are performed in a concentrated nitric acid or mixed nitric-sulfuric acids. ${ }^{33}$ Moreover, we previously suggested that the co-existed acidic group of $\mathrm{HSO}_{4}{ }^{-}$ may promote the nitration of triazol-3-one (TO) with $\mathrm{NO}_{2}{ }^{+} \cdot{ }^{30}$ It is

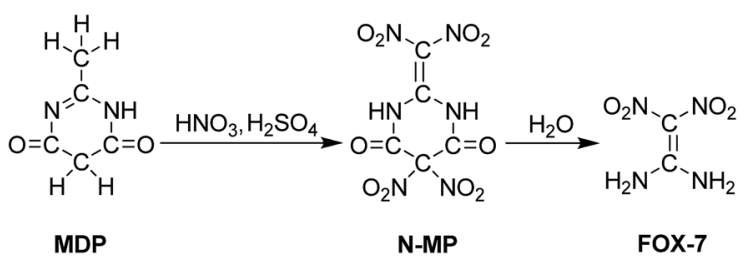

Scheme 1 Preparation strategy of FOX-7. eagerly expected and optimistically supposed that such promotion/enhancement may also exist in the nitration of MDP with $\mathrm{NO}_{2}{ }^{+}$, which needs to be verified.

In the present work, the $\mathrm{HSO}_{4}{ }^{-}$induced nitration mechanism of MDP with $\mathrm{NO}_{2}^{+}$to form N-MP is systematically investigated via DFT-B3LYP/6-311G(d,p). The possible nitration pathways are respectively excavated, in which the hypothesized induction/enhancement of $\mathrm{HSO}_{4}{ }^{-}$to the titled nitration is proposed and theoretically verified. Moreover, the impact of $-\mathrm{NO}_{2}$ attacking order on the nitration is also discerned, through which the preferential nitration pathway was illustrated. The present paper is expected to provide a better understanding on the nitration details of MDP, and will contribute great to the research and engineering tests of the preparation of FOX-7 and other nitro energetic materials.

\section{Computational details}

The calculations were performed using the Gaussian 09 software package. ${ }^{34}$ The DFT-B3LYP/6-311G(d,p) method was employed to optimize the geometries of the reactant complexes, intermediates, transition states and products in the nitration system. ${ }^{35,36}$ B3LYP/6-311G(d,p) was also applied to analyze the vibrational frequency, via which whether the obtained structures are the ones of the transition states or local minima points is verified, and the zero-point vibrational energy (ZPE) was predicted. Intrinsic reaction coordinate (IRC) ${ }^{37}$ analysis was carried out to ensure that the structure of every transition state obtained does connect the corresponding reactant and product of the (elementary) reaction. Moreover, B3LYP-D3 ${ }^{38,39}$ with a larger 6-311++G(3df,3pd) basis set was intentionally used to calculate the single-point energies of all the species to obtain more reliable energy results based on the optimized geometries. The Mulliken atomic charges ${ }^{40}$ of MDP and the relevant intermediates were also calculated via B3LYP/6-311G(d,p). The relative free energies of different stationary points obtained via B3LYP-D3/6-311++G(3df,3pd)//B3LYP/6-311G(d,p) are listed in Table 1. Additionally, the solvent effect was also simulated and primarily evaluated using the conductor-like polarizable continuum model (CPCM). ${ }^{41}$

\section{Results and discussion}

The formation of $\mathrm{NO}_{2}{ }^{+}$in the concentrated nitric acid or nitricsulfuric acids $\left(\mathrm{HNO}_{3}+2 \mathrm{H}_{2} \mathrm{SO}_{4} \rightarrow \mathrm{H}_{3} \mathrm{O}^{+}+\mathrm{NO}_{2}{ }^{+}+2 \mathrm{HSO}_{4}{ }^{-}\right)$has been investigated for years. ${ }^{33,42}$ It was suggested that $\mathrm{NO}_{2}{ }^{+}$may actually act as the nitration reagent since $\mathrm{NO}_{2}{ }^{+}$is found to be a more efficient electrophile than $\mathrm{HNO}_{3}$. Moreover, the $\mathrm{HSO}_{4}{ }^{-}$ was found to play an important role since it may effectively promote/catalyze the nitration in our recent works. ${ }^{30,31}$ Therefore, the nitration of MDP in nitric-sulfuric acids may thus be simplified as that of MDP with $\mathrm{NO}_{2}{ }^{+}$in the presence of $\mathrm{HSO}_{4}{ }^{-}$. Additionally, inspired by the publication from Koleva et al. ${ }^{25}$ it is supposed that the solvent effect from mixed acid to the titled nitration may be inapparent. Therefore, the nitration in gas phase is mainly discussed in the present work. The solvent effect is also investigated so as to explore and understand the 
Table 1 Free energies $\left(\Delta G, \mathrm{kcal} \mathrm{mol}^{-1}\right)$ for the nitration of $\mathrm{MDP}$ with $\mathrm{NO}_{2}{ }^{+}$in nitric-sulfuric acids in the gas phase ${ }^{a}$

\begin{tabular}{|c|c|c|c|c|c|c|c|c|}
\hline \multicolumn{3}{|c|}{ Path A } & \multicolumn{3}{|c|}{ Path B } & \multicolumn{3}{|c|}{ Path C } \\
\hline No. & Species & $\Delta G$ & No. & Species & $\Delta G$ & No. & Species & $\Delta G$ \\
\hline $\mathrm{A}-1$ & $\mathrm{MDP}+4 \mathrm{~S}^{b}+4 \mathrm{~N}^{c}$ & 0.0 & B-1 & $\mathrm{MDP}+4 \mathrm{~S}+4 \mathrm{~N}$ & 0.0 & $\mathrm{C}-1$ & $\mathrm{MDP}+4 \mathrm{~S}+4 \mathrm{~N}$ & 0.0 \\
\hline A-2 & $\mathrm{A}-\mathrm{IM} 1+3 \mathrm{~S}+4 \mathrm{~N}$ & -8.5 & B-2 & $\mathrm{B}-\mathrm{IM} 1+3 \mathrm{~S}+4 \mathrm{~N}$ & -1.5 & $\mathrm{C}-2$ & $\mathrm{Ca}-\mathrm{IM} 1+2 \mathrm{~S}+3 \mathrm{~N}+\mathrm{SH}$ & -180.7 \\
\hline $\mathrm{A}-3$ & $\mathrm{~A}-\mathrm{TS} 1+3 \mathrm{~S}+4 \mathrm{~N}$ & 5.3 & B-3 & $\mathrm{B}-\mathrm{TS} 1+3 \mathrm{~S}+4 \mathrm{~N}$ & 0.3 & $\mathrm{C}-3$ & $\mathrm{Ca}-\mathrm{TS} 1+2 \mathrm{~S}+3 \mathrm{~N}+\mathrm{SH}$ & -168.2 \\
\hline $\mathrm{A}-4$ & $\mathrm{~A}-\mathrm{IM} 2+3 \mathrm{~S}+4 \mathrm{~N}$ & -10.8 & B-4 & $\mathrm{B}-\mathrm{IM} 2+3 \mathrm{~S}+4 \mathrm{~N}$ & -15.0 & $\mathrm{C}-4$ & $\mathrm{Ca}-\mathrm{IM} 2+2 \mathrm{~S}+3 \mathrm{~N}+\mathrm{SH}$ & -183.0 \\
\hline$A-5$ & $\mathrm{~A}-\mathrm{IM} 3+3 \mathrm{~S}+3 \mathrm{~N}$ & -130.3 & B-5 & $\mathrm{B}-\mathrm{IM} 3+3 \mathrm{~S}+4 \mathrm{~N}$ & -14.7 & C-5 & $\mathrm{Ca}-\mathrm{IM} 3+2 \mathrm{~S}+3 \mathrm{~N}+\mathrm{SH}$ & -183.4 \\
\hline A-6 & $\mathrm{A}-\mathrm{TS} 2+3 \mathrm{~S}+3 \mathrm{~N}$ & -124.7 & B-6 & $\mathrm{B}-\mathrm{TS} 2+3 \mathrm{~S}+4 \mathrm{~N}$ & -10.9 & C-6 & $\mathrm{Ca}-\mathrm{TS} 2+2 \mathrm{~S}+3 \mathrm{~N}+\mathrm{SH}$ & -180.6 \\
\hline A-7 & A-IM4 + 3S + 3N & -169.4 & B-7 & B-IM4 + 3S + 4N & -11.2 & $\mathrm{C}-7$ & $\mathrm{Ca}-\mathrm{IM} 4+2 \mathrm{~S}+3 \mathrm{~N}+\mathrm{SH}$ & -181.4 \\
\hline A-8 & $\mathrm{A}-\mathrm{IM} 5+2 \mathrm{~S}+3 \mathrm{~N}+\mathrm{SH}^{d}$ & -180.9 & B-8 & $\mathrm{B}-\mathrm{IM} 5+3 \mathrm{~S}+3 \mathrm{~N}+\mathrm{SH}$ & -141.1 & $\mathrm{C}-8$ & Ca-IM $5+2 \mathrm{~S}+2 \mathrm{~N}+2 \mathrm{SH}$ & -303.7 \\
\hline A-9 & $\mathrm{A}-\mathrm{TS} 3+2 \mathrm{~S}+3 \mathrm{~N}+\mathrm{SH}$ & -178.0 & B-9 & $\mathrm{B}-\mathrm{TS} 3+3 \mathrm{~S}+3 \mathrm{~N}+\mathrm{SH}$ & -112.0 & C-9 & $\mathrm{Ca}-\mathrm{TS} 3+2 \mathrm{~S}+2 \mathrm{~N}+2 \mathrm{SH}$ & -274.9 \\
\hline $\mathrm{A}-10$ & $\mathrm{~A}-\mathrm{IM} 6+2 \mathrm{~S}+3 \mathrm{~N}+\mathrm{SH}$ & -194.3 & B-10 & $\mathrm{B}-\mathrm{IM} 6+3 \mathrm{~S}+3 \mathrm{~N}+\mathrm{SH}$ & -159.3 & $\mathrm{C}-10$ & $\mathrm{Ca}-\mathrm{IM} 6+2 \mathrm{~S}+2 \mathrm{~N}+2 \mathrm{SH}$ & -322.5 \\
\hline A-11 & $\mathrm{A}-\mathrm{IM} 7+3 \mathrm{~S}+2 \mathrm{~N}+\mathrm{SH}$ & -205.1 & B-11 & $\mathrm{B}-\mathrm{IM} 7+2 \mathrm{~S}+3 \mathrm{~N}+\mathrm{SH}$ & -184.0 & C-11 & $\mathrm{Ca} 1-\mathrm{IM} 7+\mathrm{S}+2 \mathrm{~N}+2 \mathrm{SH}$ & -350.0 \\
\hline A-12 & $\mathrm{A}-\mathrm{TS} 4+3 \mathrm{~S}+2 \mathrm{~N}+\mathrm{SH}$ & -182.5 & B-12 & $\mathrm{B}-\mathrm{TS} 4+2 \mathrm{~S}+3 \mathrm{~N}+\mathrm{SH}$ & -168.5 & C-12 & $\mathrm{Ca} 1-\mathrm{TS} 4+\mathrm{S}+2 \mathrm{~N}+2 \mathrm{SH}$ & -337.0 \\
\hline A-13 & $\mathrm{A}-\mathrm{IM} 8+3 \mathrm{~S}+2 \mathrm{~N}+\mathrm{SH}$ & -208.2 & B-13 & $\mathrm{B}-\mathrm{IM} 8+2 \mathrm{~S}+3 \mathrm{~N}+\mathrm{SH}$ & -173.9 & C-13 & $\mathrm{Ca} 1-\mathrm{IM} 8+\mathrm{S}+2 \mathrm{~N}+2 \mathrm{SH}$ & -348.3 \\
\hline A-14 & $\mathrm{A}-\mathrm{IM} 9+2 \mathrm{~S}+2 \mathrm{~N}+\mathrm{SH}$ & -318.7 & B-14 & B-IM9 + 2S + 2N + 2SH & -292.3 & C-14 & Ca1-IM9 + S + N + 3SH & -454.9 \\
\hline A-15 & $\mathrm{A}-\mathrm{TS} 5+2 \mathrm{~S}+2 \mathrm{~N}+\mathrm{SH}$ & -314.7 & B-15 & B-TS5 $+2 \mathrm{~S}+2 \mathrm{~N}+2 \mathrm{SH}$ & -271.6 & C-15 & $\mathrm{Ca} 1-\mathrm{TS} 5+\mathrm{S}+\mathrm{N}+3 \mathrm{SH}$ & -434.6 \\
\hline A-16 & $\mathrm{A}-\mathrm{IM} 10+2 \mathrm{~S}+2 \mathrm{~N}+\mathrm{SH}$ & -334.3 & B-16 & B-IM10 $+2 \mathrm{~S}+2 \mathrm{~N}+2 \mathrm{SH}$ & -312.6 & C-16 & Ca1-IM10 + S + N + 3SH & -473.6 \\
\hline A-17 & $\mathrm{A}-\mathrm{IM} 11+\mathrm{S}+2 \mathrm{~N}+2 \mathrm{SH}$ & -346.2 & B-17 & B-IM11 $+\mathrm{S}+2 \mathrm{~N}+2 \mathrm{SH}$ & -333.0 & $\mathrm{C}-17$ & $\mathrm{Ca} 2-\mathrm{IM} 7+\mathrm{S}+2 \mathrm{~N}+2 \mathrm{SH}$ & -346.0 \\
\hline A-18 & $\mathrm{A}-\mathrm{TS} 6+\mathrm{S}+2 \mathrm{~N}+2 \mathrm{SH}$ & -344.7 & B-18 & $\mathrm{B}-\mathrm{TS} 6+\mathrm{S}+2 \mathrm{~N}+2 \mathrm{SH}$ & -318.2 & C-18 & $\mathrm{Ca} 2-\mathrm{TS} 4+\mathrm{S}+2 \mathrm{~N}+2 \mathrm{SH}$ & -343.5 \\
\hline A-19 & $\mathrm{A}-\mathrm{IM} 12+\mathrm{S}+2 \mathrm{~N}+2 \mathrm{SH}$ & -355.8 & B-19 & B-IM12 + S + 2N + 2SH & -331.8 & C-19 & $\mathrm{Ca} 2-\mathrm{IM} 8+\mathrm{S}+2 \mathrm{~N}+2 \mathrm{SH}$ & -357.2 \\
\hline A-20 & $\mathrm{A}-\mathrm{IM} 13+\mathrm{S}+\mathrm{N}+3 \mathrm{SH}$ & -461.1 & B-20 & B-IM13 + S + N + 2SH & -445.3 & $\mathrm{C}-20$ & $\mathrm{Ca} 2-\mathrm{IM} 9+2 \mathrm{~S}+\mathrm{N}+2 \mathrm{SH}$ & -356.4 \\
\hline$A-21$ & $\mathrm{~A}-\mathrm{TS} 7+\mathrm{S}+\mathrm{N}+3 \mathrm{SH}$ & -439.2 & B-21 & $\mathrm{B}-\mathrm{TS} 7+\mathrm{S}+\mathrm{N}+2 \mathrm{SH}$ & -433.5 & $\mathrm{C}-21$ & $\mathrm{Ca} 2-\mathrm{TS} 5+2 \mathrm{~S}+\mathrm{N}+2 \mathrm{SH}$ & -333.9 \\
\hline A-22 & $\mathrm{A}-\mathrm{IM} 14+\mathrm{S}+\mathrm{N}+3 \mathrm{SH}$ & -487.3 & B-22 & B-IM14 + S + N + 2SH & -475.4 & $\mathrm{C}-22$ & $\mathrm{Ca} 2-\mathrm{IM} 10+2 \mathrm{~S}+\mathrm{N}+2 \mathrm{SH}$ & -357.9 \\
\hline A-23 & A-IM15 + N + 3SH & -512.9 & B-23 & B-IM15 $+\mathrm{S}+\mathrm{N}+2 \mathrm{SH}$ & -497.6 & C-23 & $\mathrm{Ca} 2-\mathrm{IM} 11+\mathrm{S}+\mathrm{N}+2 \mathrm{SH}$ & -474.2 \\
\hline A-24 & A-TS8 $+\mathrm{N}+3 \mathrm{SH}$ & -509.7 & B-24 & $\mathrm{B}-\mathrm{TS} 8+\mathrm{S}+\mathrm{N}+2 \mathrm{SH}$ & -495.3 & $\mathrm{C}-24$ & $\mathrm{Ca} 2-\mathrm{TS} 6+\mathrm{S}+\mathrm{N}+2 \mathrm{SH}$ & -468.4 \\
\hline A-25 & A-IM16 + N + 3SH & -526.3 & B-25 & B-IM16 + S + N + 2SH & -511.3 & C-25 & $\mathrm{Ca} 2-\mathrm{IM} 12+\mathrm{S}+\mathrm{N}+2 \mathrm{SH}$ & -490.2 \\
\hline A-26 & $\mathrm{A}-\mathrm{IM} 17+4 \mathrm{SH}$ & -620.3 & B-26 & B-IM17 + S + 3SH & -500.7 & C-26 & $\mathrm{Cb}-\mathrm{IM} 1+2 \mathrm{~S}+3 \mathrm{~N}+\mathrm{SH}$ & -176.3 \\
\hline A-27 & $\mathrm{A}-\mathrm{TS} 9+4 \mathrm{SH}$ & -600.7 & B-27 & B-TS9 $+\mathrm{S}+3 \mathrm{SH}$ & -481.1 & $\mathrm{C}-27$ & $\mathrm{Cb}-\mathrm{TS} 1+2 \mathrm{~S}+3 \mathrm{~N}+\mathrm{SH}$ & -161.5 \\
\hline \multirow[t]{5}{*}{ A-28 } & A-IM18(N-MP) + 4SH & -637.0 & B-28 & B-IM18 + S + 3SH & -502.7 & $\mathrm{C}-28$ & $\mathrm{Cb}-\mathrm{IM} 2+2 \mathrm{~S}+3 \mathrm{~N}+\mathrm{SH}$ & -176.4 \\
\hline & & & B-29 & B-IM19 + 3SH & -624.7 & C-29 & $\mathrm{Cb}-\mathrm{IM} 3+2 \mathrm{~S}+2 \mathrm{~N}+\mathrm{SH}$ & -290.5 \\
\hline & & & B-30 & $\mathrm{B}-\mathrm{TS} 10+3 \mathrm{SH}$ & -615.5 & C-30 & $\mathrm{Cb}-\mathrm{TS} 2+2 \mathrm{~S}+2 \mathrm{~N}+\mathrm{SH}$ & -282.6 \\
\hline & & & B-31 & B-IM20 + 3SH & -639.8 & $\mathrm{C}-31$ & $\mathrm{Cb}-\mathrm{IM} 4+2 \mathrm{~S}+2 \mathrm{~N}+\mathrm{SH}$ & -324.3 \\
\hline & & & B-32 & $\mathrm{N}-\mathrm{MP}+4 \mathrm{SH}$ & -637.0 & & & \\
\hline
\end{tabular}

${ }^{a}$ ZPG was obtained via DFT at the B3LYP/6-311G(d,p) level. The energy value $(\Delta G)$ was obtained at the B3LYP-D3/6-311++G(3df,3pd)//B3LYP/6$311 \mathrm{G}(\mathrm{d}, \mathrm{p})$ level. ${ }^{b}$ Here, $\mathrm{HSO}_{4}{ }^{-}$is abbreviated or denoted as $\mathrm{S}^{c}{ }^{c} \mathrm{HNO}_{3}$ is denoted as $\mathrm{N}^{d}{ }^{d} \mathrm{H}_{2} \mathrm{SO}_{4}$ is denoted as SH.

impacts of the medium on the titled nitration. Based on such cognition, the nitration mechanism of MDP with $\mathrm{NO}_{2}{ }^{+}$to form N-MP is investigated, so does the impact of the nitration order. In view of the Mulliken atomic charges of MDP (Table S1†) and our recent work, ${ }^{30}$ we focus our interests on the C-nitration pathway(s), namely only the attacking of methylene $\mathrm{C} 4$ and methyl C10 in MDP by $\mathrm{NO}_{2}{ }^{+}$are considered. Such C-nitration pathways are systematically discussed in the present work.

\subsection{Nitration mechanism of MDP}

3.1.1 Preferential dinitration on methyl group. In this path, it is supposed that when methyl C10 in MDP is completely dinitrated, methylene $\mathrm{C} 4$ comes to be attacked by $\mathrm{NO}_{2}{ }^{+}$till four $-\mathrm{NO}_{2}$ are successfully introduced.

We suggest that the nitration of MDP with $\mathrm{NO}_{2}{ }^{+}$may be induced/catalyzed by the co-existed $\mathrm{HSO}_{4}{ }^{-}$. Such $\mathrm{HSO}_{4}{ }^{-}$ induced nitration of MDP is denoted as path A. The potential energy profiles and the corresponding optimized geometries are shown in Fig. 1 and 2, respectively. While to verify the expected induction/enhancement of $\mathrm{HSO}_{4}{ }^{-}$, a hypothetical direct nitration path way of MDP (without any assistance/cooperation of $\mathrm{HSO}_{4}{ }^{-}$in the $\mathrm{NO}_{2}{ }^{+}$attacking step, denoted as path $\mathrm{A1}^{\prime}$ ) is also studied and presented in Fig. S1.†

As shown in Fig. $\mathrm{S} 1, \uparrow$ it is seen that the $\mathrm{NO}_{2}{ }^{+}$attacking and the hydrogen transferring (H-transferring) may occur simultaneously in the direct nitration of MDP (path $\mathrm{A}^{\prime}$ ). The activation free energy $\left(\Delta G^{\neq}\right)$associated with this $\mathrm{NO}_{2}{ }^{+}$attacking is 62.6 kcal $\mathrm{mol}^{-1}$, indicating that path $\mathrm{A}^{\prime}$ is severely unlikely to occur. While as shown in Fig. 1 and 2, it is surprisingly found that the $\Delta G^{\neq}$for the $\mathrm{NO}_{2}{ }^{+}$attacking (A-IM3 $\rightarrow$ A-IM4) is merely $5.6 \mathrm{kcal}$ $\mathrm{mol}^{-1}$. An unexpected sharp decrease of $57 \mathrm{kcal} \mathrm{mol}^{-1}$ is achieved, indicating that the nitration may be effectively promoted/ enhanced by $\mathrm{HSO}_{4}{ }^{-}$. Such $\mathrm{NO}_{2}{ }^{+}$attacking is definitely much more favorable than that in path $\mathrm{A}^{\prime}$ (Fig. $\mathrm{S} 1 \dagger$ ).

The schematic energy diagram of the $\mathrm{HSO}_{4}{ }^{-}$-induced $\mathrm{NO}_{2}{ }^{+}$ attacking to MDP is shown in Fig. S2. $\dagger$ As shown in Fig. S2, $\dagger$ the $\Delta G^{\neq}$for the $\mathrm{HSO}_{4}{ }^{-}$-induced $\mathrm{NO}_{2}{ }^{+}$attacking is $46.1 \mathrm{kcal} \mathrm{mol}^{-1}$, leading to a decrease of $16.5 \mathrm{kcal} \mathrm{mol}^{-1}$ as compared with that in path $\mathrm{A} 1^{\prime}$. Such a high $\Delta G^{\neq}$value indicates that path $\mathrm{A} 1$ (Fig. S2†) is unlikely to occur. It is supposed that the decrease in 


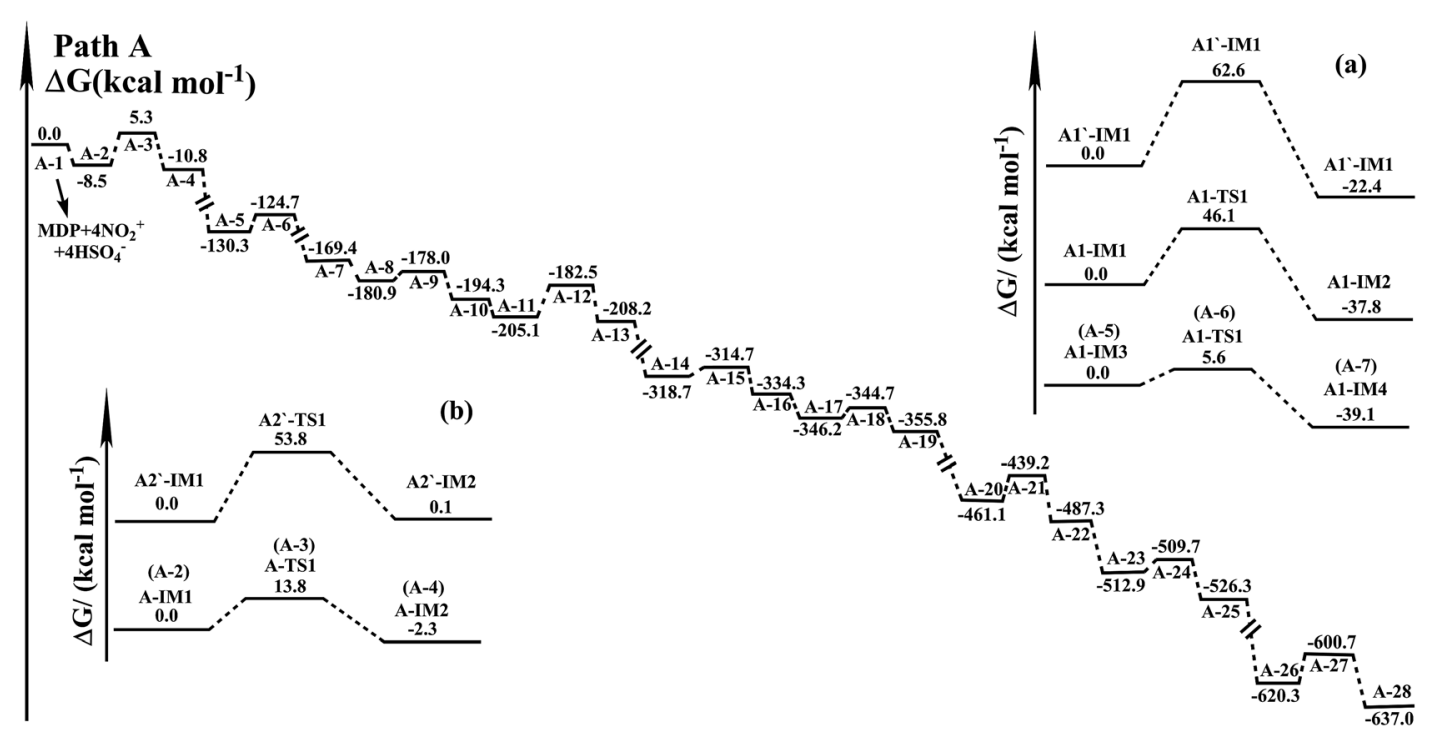

Fig. 1 Schematic energy diagram for potential energy surface of the preferential dinitration on methyl group of MDP in the gas phase predicted via B3LYP-D3/6-311++G(3df,3pd)//B3LYP/6-311G(d,p). For brevity, the systems with different species are numbered/denoted from "A-1" to "A28 ". The correspondence of the serial number and the systems is listed in Table 1. Insert (a): the potential energy surfaces of the first $\mathrm{NO}_{2}{ }^{+}$ attacking step of MDP. Insert (b): the potential energy surfaces of the $\mathrm{H}$-transferring step of MDP.

$\Delta G^{\neq}$may be derived from the induction of $\mathrm{HSO}_{4}{ }^{-}$. However, such decrease is not as much as what was expected.

We supposed that if $\mathrm{H} 11$ in $\mathrm{C} 10$ transfers to N5, the $\mathrm{HSO}_{4}{ }^{-}$induced nitration step may occur more likely for that such $\mathrm{H}^{-}$ transferring may obviously decrease the steric hindrance and increase the nucleophilicity of C10. The schematic energy diagram of the direct $\mathrm{H}$-transferring (without the assistance of $\left.\mathrm{HSO}_{4}{ }^{-}\right)$is shown in Fig. $\mathrm{S} 3 \uparrow\left(\Delta G^{\neq}=53.8 \mathrm{kcal} \mathrm{mol}^{-1}\right)$. While as compared with the $\mathrm{HSO}_{4}{ }^{-}$-induced $\mathrm{H}$-transferring (A-IM1 $\rightarrow$ AIM2, Fig. $2, \Delta G^{\neq}=13.8 \mathrm{kcal} \mathrm{mol}^{-1}$ ), a dramatical decrease of approximately $40.0 \mathrm{kcal} \mathrm{mol}^{-1}$ is obtained (insert (b), Fig. 1), indicating that the $\mathrm{HSO}_{4}{ }^{-}$-induced $\mathrm{H}$-transferring is much more likely to occur. In view that similar induction/promotion of $\mathrm{HSO}_{4}{ }^{-}$is also found in the $\mathrm{H}$-transferring of the mononitrated MDP (A-IM5 $\rightarrow$ A-IM6, Fig. 2) if compared with the direct $\mathrm{H}$-transferring of the mono-nitrated MDP (A3'-IM1 $\rightarrow$ A3'-IM2, Fig. S4 $\dagger$ ), we believe that the promotion/enhancement of the $\mathrm{HSO}_{4}{ }^{-}$induction to $\mathrm{H}$-transferring is verified.

We supposed that the next $\mathrm{NO}_{2}^{+}$attacking and the $\mathrm{H}^{-}$ abstracting may occur simultaneously after A-IM2 is obtained. The $\mathrm{HSO}_{4}{ }^{-}$-induced $\mathrm{NO}_{2}{ }^{+}$attacking along with the $\mathrm{H}$ abstracting is shown in Fig. 2 (A-IM3 $\rightarrow$ A-IM4). As shown in Fig. 2, it is seen that with the approach of the $\mathrm{HSO}_{4}{ }^{-} \cdots \mathrm{NO}_{2}{ }^{+}$to C10 and H21, an eight-membered transition state of A-TS2 is formed by $\mathrm{C} 10-\mathrm{N} 13-\mathrm{O} 23-\mathrm{S} 15-\mathrm{O} 22-\mathrm{H} 21-\mathrm{N} 5-\mathrm{C} 2$, in which one $\mathrm{NO}_{2}{ }^{+}$(N13) is added (to C10), and one hydrogen (H21) is synchronously transferred (from N5 to O22).

The $\mathrm{NO}_{2}{ }^{+}$attacking step in every nitration path is compared and discussed. The $\Delta G^{\neq}$in A-IM3 $\rightarrow$ A-IM4 (Fig. 2) is much lower than that in either A1'-IM1 $\rightarrow$ A1'-IM2 (Fig. S1 $\dagger$ ) or A1-IM1 $\rightarrow$ A1-IM2 (Fig. S2 $\dagger$ ). Clearly (insert (a), Fig. 1), A-IM3 $\rightarrow$ A-IM4 is much more favorable than $\mathrm{A}^{\prime}$-IM1 $\rightarrow$ A1'-IM2 and A1-IM1 $\rightarrow$ A1-IM2. It is inferred that the H-transferring must be the prerequisite to the nitration of MDP. More importantly, both the $\mathrm{H}$-transferring and the $\mathrm{NO}_{2}{ }^{+}$attacking must be synergistically promoted/enhanced by $\mathrm{HSO}_{4}{ }^{-}$via a unique induction. Such hypothesis is well supported by the results of the Mulliken atomic charges of the relevant pre-intermediates in the $\mathrm{NO}_{2}{ }^{+}$ attacking steps listed in Table $\mathrm{S} 1 . \dagger$ In Table $\mathrm{S} 1, \dagger$ the atomic charge of C10 in A-IM3 is the most negative among that in the three pre-intermediates. It is indicated that the C10 in A-IM3 may have the best nucleophilicity to be favorably attacked by $\mathrm{NO}_{2}{ }^{+}$. As compared with the direct nitration (Fig. S1 $\dagger$ ), it is seen that without H-transferring of MDP (C10 to N5 in Fig. S2 $\dagger$ ), the nucleophilicity of C10 may also distinctly increase if the induction of $\mathrm{HSO}_{4}{ }^{-}$to the $\mathrm{NO}_{2}{ }^{+}$attacking is considered. While the increase of the atomic charge of C10 in A1-IM1 is found much inferior to that in A-IM3, in which the $\mathrm{H}$-transferring and $\mathrm{HSO}_{4}{ }^{-}$induced $\mathrm{NO}_{2}{ }^{+}$attacking are both considered.

After the mono-nitration of MDP in Fig. 2 (A-IM3 $\rightarrow$ A-IM4), and the subsequent $\mathrm{HSO}_{4}{ }^{-}$induced $\mathrm{H}$-transferring in mononitrated MDP (A-IM5 $\rightarrow$ A-IM6), the second $\mathrm{NO}_{2}^{+}$attacking occurs (A-IM7 $\rightarrow$ A-IM8). While it seems that $\mathrm{HSO}_{4}{ }^{-}$does not participate the second $\mathrm{NO}_{2}{ }^{+}$attacking partly due to the steric hindrance from the prior-introduced $-\mathrm{NO}_{2}$ on the same $\mathrm{C}$ atom of C10. Luckily, the $\Delta G^{\neq}$in the second $\mathrm{NO}_{2}{ }^{+}$attacking step is found fairly moderate $\left(22.6 \mathrm{kcal} \mathrm{mol}^{-1}\right)$. Possible reason is that the second $\mathrm{NO}_{2}{ }^{+}$may be attracted by the $\mathrm{O}$ atom in the previously introduced $-\mathrm{NO}_{2}$, resulting in the formation of the complex (A-IM7, Fig. 2) and facilitating the subsequent attacking of $\mathrm{NO}_{2}{ }^{+}$to $\mathrm{C} 10$ site (A-IM7 $\rightarrow$ A-IM8, Fig. 2). When the rest $\mathrm{H}$ atom on $\mathrm{C} 10$ is abstracted, the preferential dinitration on this methyl group is achieved.

It is reported that when $\mathrm{NO}_{2}{ }^{+}$is employed as the nitration agent, the nitro group in the product may be further protonated to $-\mathrm{NOOH}$, followed by that the proton in the $-\mathrm{NOOH}$ may be 

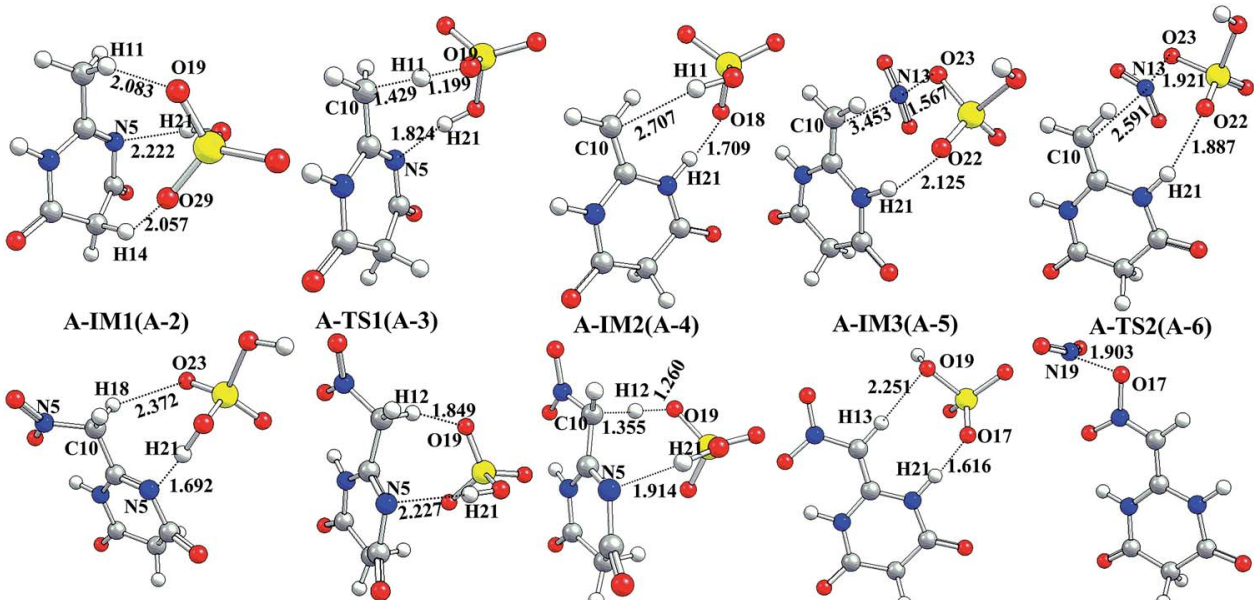

A-TS1(A-3)
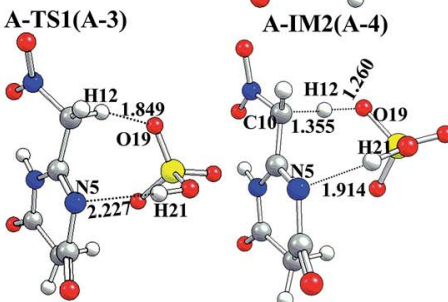

A-IM3(A-5)

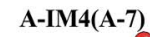

A-IM5(A-8)
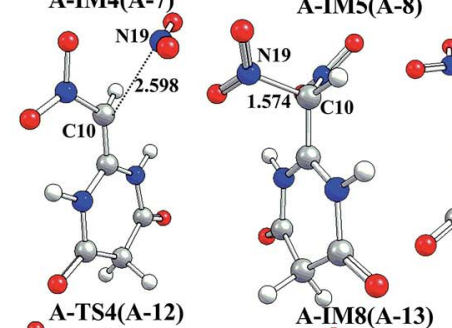

A-TS3(A-9)

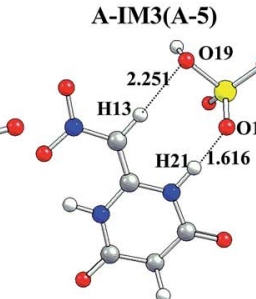

A-IM6(A-10)

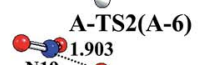

$2(A-6)$

N19 017

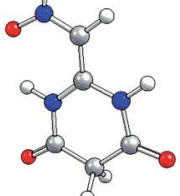

A-IM7(A-11)
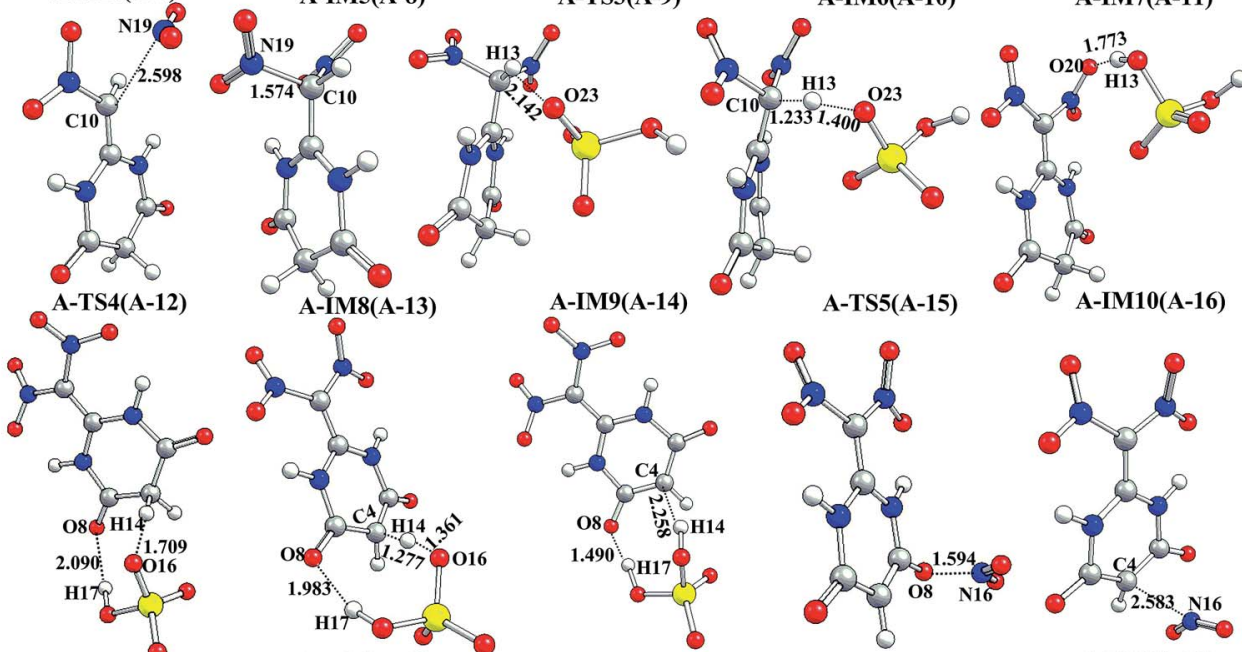

A-IM11( $8-17)$

A-TS6(A-18)
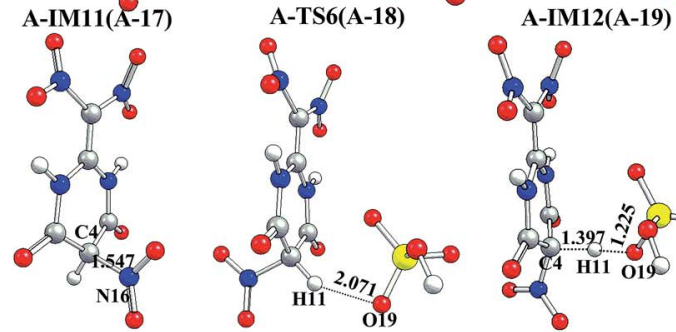

A-TS5(A-15)

RSC Advances
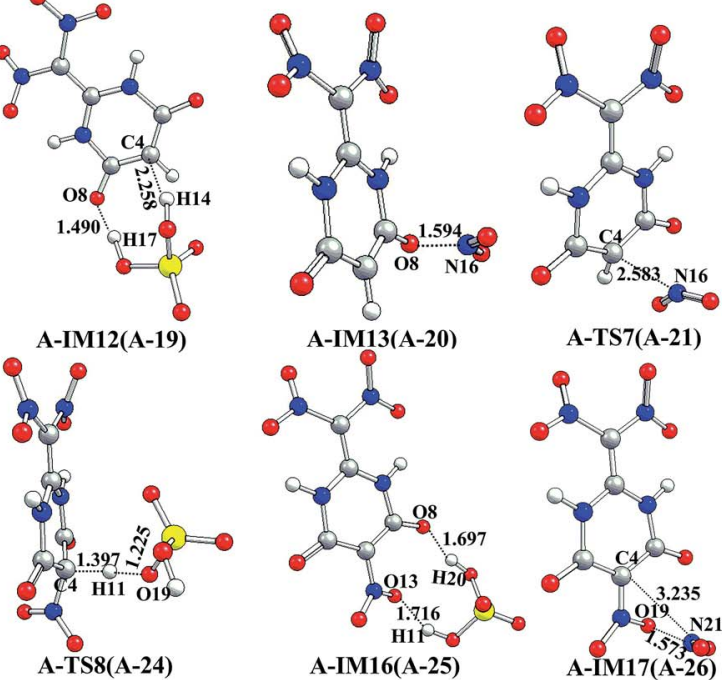

A-TS7(A-21)
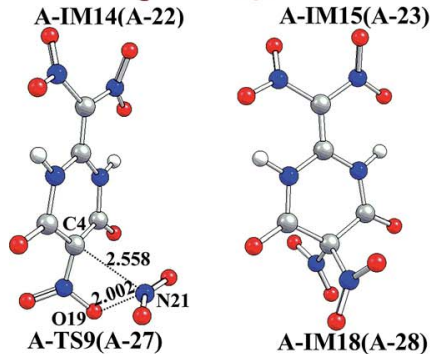

A-IM16(A-25)

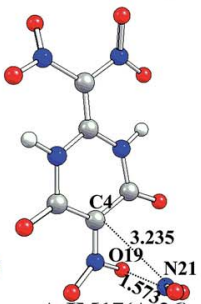

A-IM17(A-26)

Fig. 2 Optimized geometries of species in the preferential dinitration on methyl group of MDP in the gas phase calculated via B3LYP/6-311G(d,p) (bond lengths are in angstrom). The serial number (in parentheses) represents the system of corresponding species listed in Table 1.

easily abstracted in the presence of acidic group(s). ${ }^{24,30,31}$ It is inferred that when the rest $\mathrm{H}$ atom on $\mathrm{C} 10$ is transferred to the nitro group, the $\mathrm{H}$-abstracting may be successfully performed. Such process is studied in the present work. The schematic energy diagram of the H-transferring of the dinitrated MDP is shown in Fig. S5† (from $\mathrm{C} 10$ to O20). It is seen that without the assistance of $\mathrm{HSO}_{4}^{-}$, the $\Delta G^{\neq}$in the H-transferring step is found to be $40.3 \mathrm{kcal} \mathrm{mol}^{-1}$ (A4'-IM1 $\rightarrow \mathrm{A}^{\prime}$-IM2, Fig. S5†). While when the $\mathrm{HSO}_{4}{ }^{-}$induction/promotion is considered, it is clearly seen that $\Delta G^{\neq}$in the H-abstracting step (A-IM9 $\rightarrow$ A- 
IM10, Fig. 1 and 2) dramatically decreases to $2.3 \mathrm{kcal} \mathrm{mol}^{-1}$. Definitely, the $\mathrm{HSO}_{4}{ }^{-}$induced $\mathrm{H}$-abstracting in Fig. 2 (A-IM9 $\rightarrow$ A-IM10) is much more favorable than the H-transferring in Fig. S5† (A4'-IM1 $\rightarrow$ A4'-IM2). We thus strongly suggest that the $\mathrm{H}$-abstracting may be effectively induced/promoted by $\mathrm{HSO}_{4}{ }^{-}$, which is readily adopted in the rest steps of path A.

The successful obtaining of A-IM10 indicates that C10 in MDP has been preferentially dinitrated. Hereafter, the nitration on $\mathrm{C} 4$ is discussed.

We once supposed that the next nitration step may be similar to A-IM3 $\rightarrow$ A-IM4, in which the $\mathrm{NO}_{2}{ }^{+}$attacking on the $\mathrm{C} 4$ may occur simultaneously with the $\mathrm{H}$-abstracting in such step. However, such assumption was not supported by the calculation, though several methods were attempted and weeks of time were paid. While, it can be inferred that the $\mathrm{H}$ atom(s) on $\mathrm{C} 4$ may be distinctly activated by the two adjacent carbonyl groups, for that the $\mathrm{H}$-abstracting on the $\mathrm{C} 4$ is found quite likely to occur in the presence of $\mathrm{HSO}_{4}{ }^{-}$(A-IM11 $\rightarrow$ A-IM12, $\Delta G^{\neq}=1.5$ kcal $\mathrm{mol}^{-1}$, Fig. 2 and Table 1). Subsequently, the $\mathrm{NO}_{2}{ }^{+}$ attacking to C4 site occurs (A-IM13 $\rightarrow$ A-IM14), in which the $\Delta G^{\neq}$is $21.9 \mathrm{kcal} \mathrm{mol}^{-1}$. In a word, as to the introduction of the third $-\mathrm{NO}_{2}$ to the methylene $\mathrm{C} 4$ in MDP (A-IM11 $\rightarrow$ A-IM14) is concerned, though the $\mathrm{H}$-abstracting and the $\mathrm{NO}_{2}{ }^{+}$attacking may not occur simultaneously, it is suggested that A-IM11 $\rightarrow$ AIM14 is definitely promoted by $\mathrm{HSO}_{4}{ }^{-}$.

The introduction of the fourth $-\mathrm{NO}_{2}$ to $\mathrm{C} 4$ (A-IM15 $\rightarrow$ A-IM18) is found to be quite similar to that of the third one. The fourth nitration is supposed to begin with the $\mathrm{HSO}_{4}{ }^{-}$-induced $\mathrm{H}$ abstracting step (A-IM15 $\rightarrow$ A-IM16) with a $\Delta G^{\neq}$of $3.2 \mathrm{kcal}$ $\mathrm{mol}^{-1}$. Followed by the $\mathrm{NO}_{2}{ }^{+}$attacking to $\mathrm{C} 4$ site (A-IM17 $\rightarrow$ AIM18), which has a $\Delta G^{\neq}$of $19.6 \mathrm{kcal} \mathrm{mol}^{-1}$, after which the targeted nitration product of N-MP is eventually achieved. Clearly, the second $\mathrm{NO}_{2}{ }^{+}$attacking to C4 step (path A, A-IM7 $\rightarrow$ A-IM8) is the rate-determining step, as shown in Fig. 1.

Based on the above mentioned calculation, it is strongly suggested that the co-existed acidic group of $\mathrm{HSO}_{4}{ }^{-}$may effectively induce/catalyze the nitration process. We find that besides the $\mathrm{NO}_{2}{ }^{+}$attacking step is promoted as was expected, the $\mathrm{H}$-transferring as well as the $\mathrm{H}$-abstracting is surprisingly enhanced by $\mathrm{HSO}_{4}^{-}$in the nitration process in path $\mathrm{A}$. Moreover, it is reported that FOX-7 could been prepared via the nitration of MDP in the nitric-sulfuric acids with high yield, even though the reaction time is relative short along with the temperature is low. ${ }^{5,6}$ Such facts indicated that the activity free energy of the nitration should be considerably low, and the $\mathrm{HSO}_{4}{ }^{-}$-induced path A may be more favorable way than the direct path, which is in very good agreement with the experimental results. ${ }^{6}$ Additionally, in view of the fact that a higher $\mathrm{H}_{2} \mathrm{SO}_{4}$ concentration may benefit an easier formation of $\mathrm{NO}_{2}{ }^{+}$along with a more difficult dissociation of $\mathrm{H}_{2} \mathrm{SO}_{4}$ to form $\mathrm{HSO}_{4}{ }^{-}$, the concentration of $\mathrm{H}_{2} \mathrm{SO}_{4}$ should be well controlled.

To the best of our knowledge, similar acidic group-induced nitration has not been reported by others so far. It is such unique induction/enhancement of $\mathrm{HSO}_{4}{ }^{-}$to the $\mathrm{NO}_{2}{ }^{+}$attacking, $\mathrm{H}$-transferring and $\mathrm{H}$-abstracting that dramatically decreases the $\Delta G^{\neq}$, effectively promotes the formation of N-MP, and thus is specifically preferred in the rest part of the present work.

3.1.2 Preferential dinitration on methylene group. We supposed that when the methylene $\mathrm{C} 4$ is completely dinitrated, the $\mathrm{C} 10$ begins to be attacked by $\mathrm{NO}_{2}{ }^{+}$till N-MP is successfully achieved. It is expected that $\mathrm{HSO}_{4}{ }^{-}$may also significantly promote the nitration. Such an $\mathrm{HSO}_{4}{ }^{-}$-induced pathway of the preferential dinitration on $\mathrm{C} 4$ in the nitration of MDP is denoted as path $\mathrm{B}$. The optimized geometries and the corresponding potential energy profiles are shown in Fig. 3 and 4, respectively.

As is seen in Fig. 3 and 4, the introduction of the two $-\mathrm{NO}_{2}$ to C4 (B-IM1 $\rightarrow$ B-IM10) in this path is exactly similar to that in path A (A-IM11 $\rightarrow$ A-IM18) except that the H-abstracting (B-IM1 $\rightarrow$ B-IM4) may be aided by a cooperated H-transferring. Clearly, path B starts with an H-transferring-aided H-abstracting step, which is somewhat different to what is mentioned in path A. During the approaching of $\mathrm{HSO}_{4}{ }^{-}$to MDP, the close of $\mathrm{H} 13$ on C4 to $\mathrm{O} 18$ occurs simultaneously with that of H19 to O8. After an eight-centered transition state of B-TS1, B-IM2 forms with a $\Delta G^{\neq}$of $1.8 \mathrm{kcal} \mathrm{mol}^{-1}$. Then $\mathrm{H} 19$ on $\mathrm{O} 8$ is easily abstracted by O18 in $\mathrm{HSO}_{4}{ }^{-}$(B-IM3 $\rightarrow$ B-IM4,$\Delta G^{\neq}=3.8 \mathrm{kcal} \mathrm{mol}^{-1}$ ) and the $\mathrm{H}$-abstracting is achieved, followed by $\mathrm{C} 4$ is attacked. It is found that the $\Delta G^{\neq}$in the subsequent first $\mathrm{NO}_{2}^{+}$attacking to $\mathrm{C} 4$ (BIM5 $\rightarrow$ B-IM6) is $29.1 \mathrm{kcal} \mathrm{mol}^{-1}$, which is higher than that in A-IM13 $\rightarrow$ A-IM14 in path A $\left(\Delta G^{\neq}=20.9 \mathrm{kcal} \mathrm{mol}^{-1}\right)$. After the $\mathrm{HSO}_{4}{ }^{-}$-induced $\mathrm{H}$-abstracting (B-IM7 $\rightarrow$ B-IM8, $\Delta G^{\neq}=15.5$ kcal mol${ }^{-1}$ ) and the second $\mathrm{NO}_{2}^{+}$attacking to $\mathrm{C} 4$ (B-IM9 $\rightarrow$ BIM10, $\Delta G^{\not \neq}=20.7 \mathrm{kcal} \mathrm{mol}^{-1}$ ), the methylene $\mathrm{C} 4$ in MDP is preferentially dinitrated.

The introduction of the two $-\mathrm{NO}_{2}$ to $\mathrm{C} 10$ in this path (B-IM11 $\rightarrow$ B-IM20) is similar to that in path A (A-IM1 $\rightarrow$ A-IM10, Fig. 1), and mainly includes five steps. It is seen that the $\Delta G^{\neq}$in the $\mathrm{HSO}_{4}{ }^{-}$-induced H-transferring (B-IM11 $\rightarrow$ B-IM12) is $14.8 \mathrm{kcal}$ $\mathrm{mol}^{-1}$. After the $\mathrm{H}$-transferring is performed, the $\mathrm{NO}_{2}{ }^{+}$attacking to $\mathrm{C} 10$ occurs simultaneously with the $\mathrm{H}$-abstracting (B-IM13 $\rightarrow$ B-IM14, $\Delta G^{\neq}=11.8 \mathrm{kcal} \mathrm{mol}^{-1}$ ), which leads to the introduction of the third $-\mathrm{NO}_{2}$ to MDP. After the $\mathrm{HSO}_{4}{ }^{-}$-induced $\mathrm{H}$ transferring (B-IM15 $\rightarrow$ B-IM16, $\Delta G^{\neq}=2.3 \mathrm{kcal} \mathrm{mol}^{-1}$ ), C10 is attacked by NO${ }_{2}^{+}$(B-IM17 $\rightarrow$ B-IM18, $\Delta G^{\neq}=19.6 \mathrm{kcal} \mathrm{mol}^{-1}$ ). Followed by $\mathrm{H} 13$ in $\mathrm{C} 10$ is abstracted by $\mathrm{HSO}_{4}{ }^{-}$(B-IM19 $\rightarrow$ BIM20, $\Delta G^{\neq}=9.2 \mathrm{kcal} \mathrm{mol}^{-1}$ ), N-MP forms.

3.1.3 Crossed nitration. We supposed that $\mathrm{C} 4$ and $\mathrm{C} 10$ in MDP are nitrated crosswise by $\mathrm{NO}_{2}{ }^{+}$under the induction of $\mathrm{HSO}_{4}{ }^{-}$. Such $\mathrm{HSO}_{4}{ }^{-}$-induced crossed nitration pathway is denoted as path $\mathrm{C}$. In this path two sub-pathways are proposed according to the $\mathrm{C}$ atom that the $\mathrm{NO}_{2}{ }^{+}$firstly attacks. If the $\mathrm{C} 10$ is firstly attacked, the corresponding sub-pathway is denoted as path Ca. Similarly, if the C4 is firstly attacked, the sub-pathway is denoted as path $\mathrm{Cb}$. The optimized geometries and the corresponding potential energy profiles are shown in Fig. 5 and 6, respectively.

Path $\mathrm{Ca}$. The introduction of the first $-\mathrm{NO}_{2}$ to $\mathrm{C} 10$ in this path is identical to that in path A (A-IM1 $\rightarrow$ A-IM4, Fig. 2), in which the mononitrated MDP is obtained, followed by Ca-IM1 (Fig. 5) forms. Then, the second $-\mathrm{NO}_{2}$ may be introduced to $\mathrm{C} 4$, resulting in the formation of Ca-IM6 (Fig. 2). While since the third $-\mathrm{NO}_{2}$ may be introduced to either $\mathrm{C} 4$ or $\mathrm{C} 10$, the 

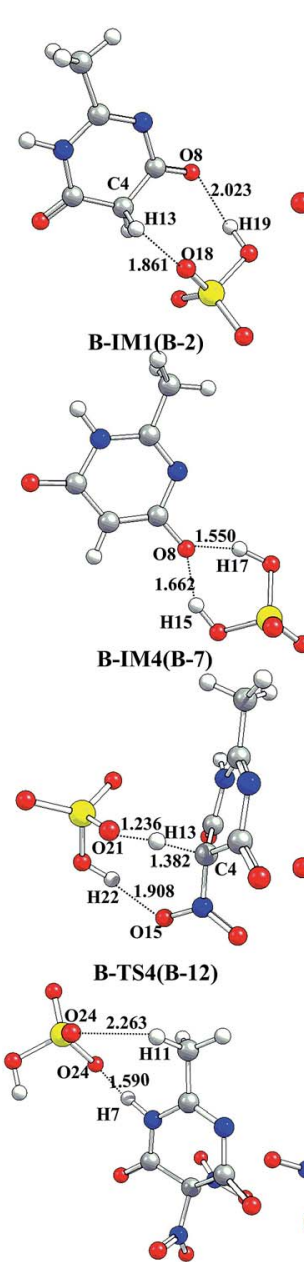

M11(B-17)

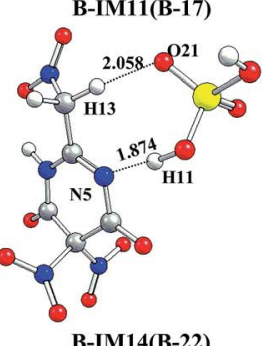

B-IM14(B-22)

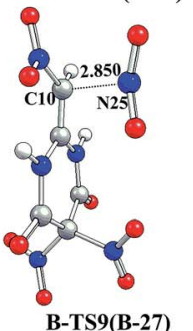

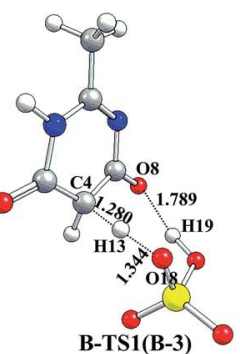
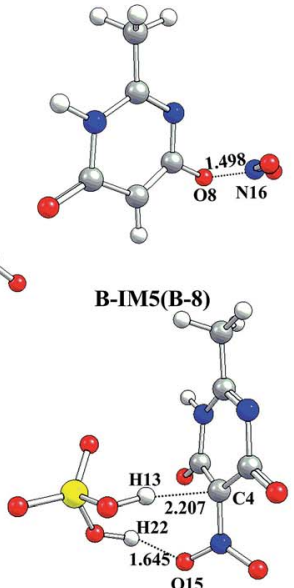

B-IM8(B-13)
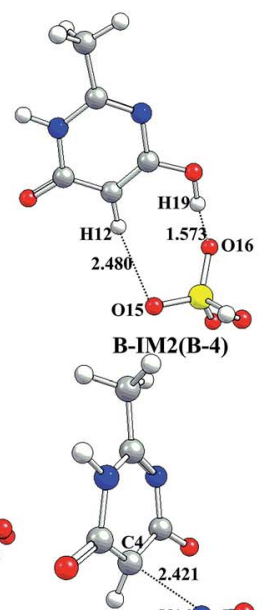

$\mathrm{N} 16=$

B-TS3(B-9)

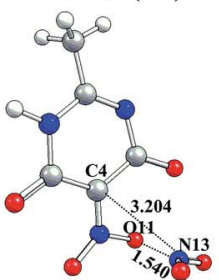

B-IM9(B-14)

0248
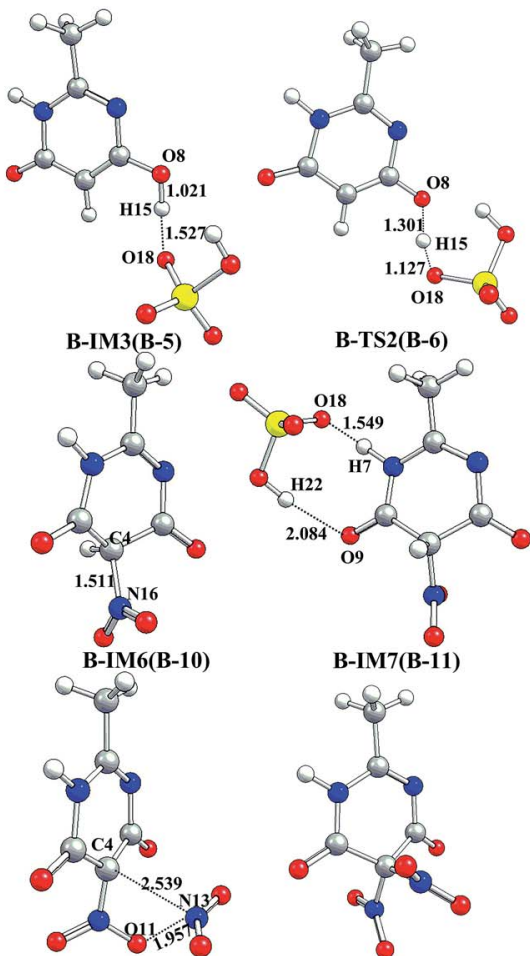

B-TS5(B-15)

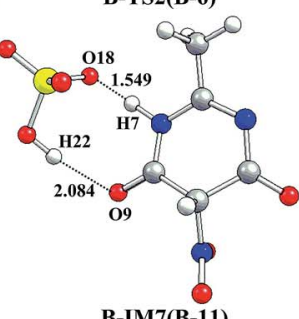

B-IM7(B-11)

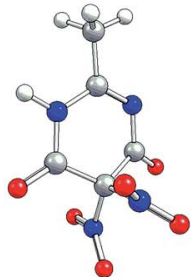

B-IM10(B-16)

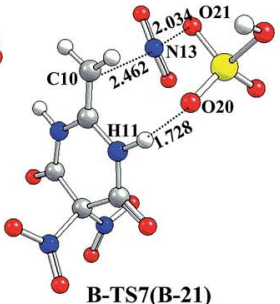

B-TS6(B-18)
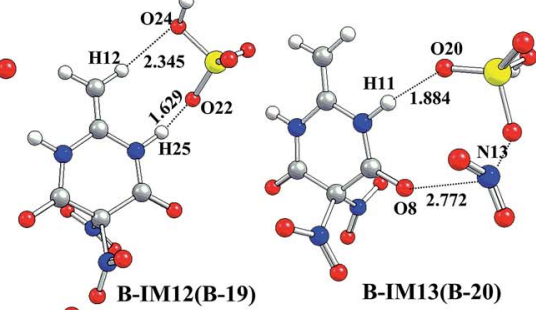

B-TS7(B-21)
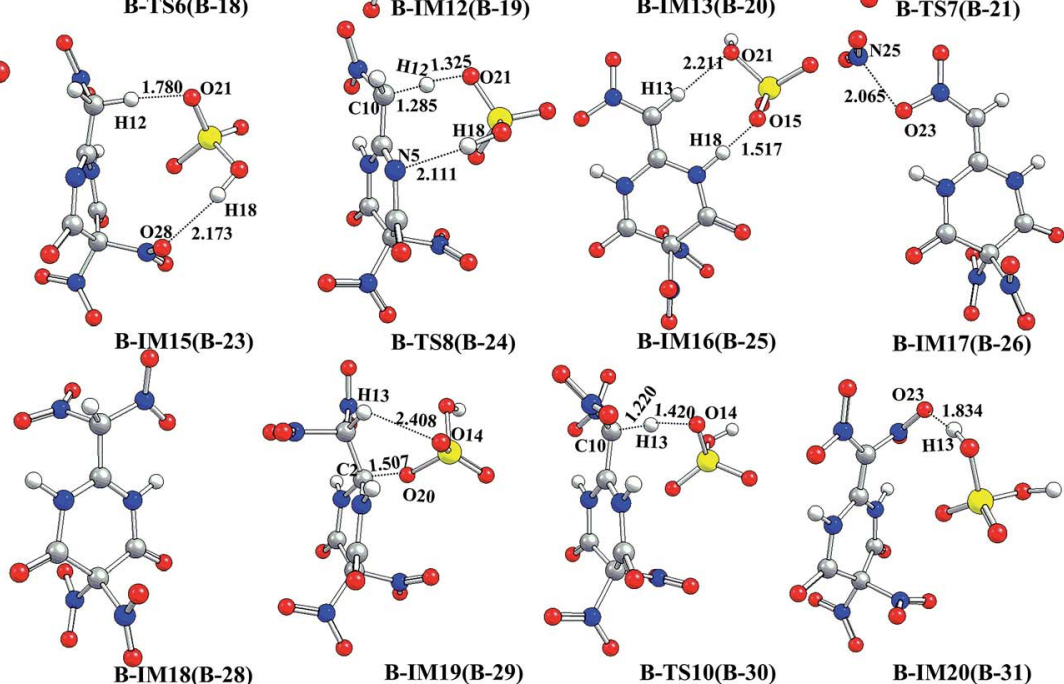

Fig. 3 Optimized geometries of species in the preferential dinitration on methylene group of MDP calculated via B3LYP/6-311G(d,p) (bond lengths are in angstrom). The serial number (in parentheses) represents the system of corresponding species listed in Table 1.

corresponding paths are denoted as $\mathrm{Ca} 1$ and $\mathrm{Ca} 2$. Clearly, the introduction of the third $-\mathrm{NO}_{2}$ may dominate how the last $-\mathrm{NO}_{2}$ is introduced. If the former follows $\mathrm{Ca} 1 \mathrm{path}$, the introduction of the last $-\mathrm{NO}_{2}$ may be identical to that in path B (B-IM15 $\rightarrow$ BIM20). By the same token, if the former follows Ca2 path, the last $-\mathrm{NO}_{2}$ may be introduced identically to that in path $\mathrm{A}(\mathrm{A}-$ IM15 $\rightarrow$ A-IM18).

As shown in Fig. 5 and 6, after H-transferring (Ca-IM1 $\rightarrow$ CaIM2, $\Delta G^{\neq}=12.5 \mathrm{kcal} \mathrm{mol}^{-1}$ ) aided $\mathrm{H}$-abstracting process (CaIM3 $\rightarrow$ Ca-IM4, $\Delta G^{\neq}=2.8 \mathrm{kcal} \mathrm{mol}{ }^{-1}$ ), $\mathrm{H} 13$ in $\mathrm{C} 4$ is 


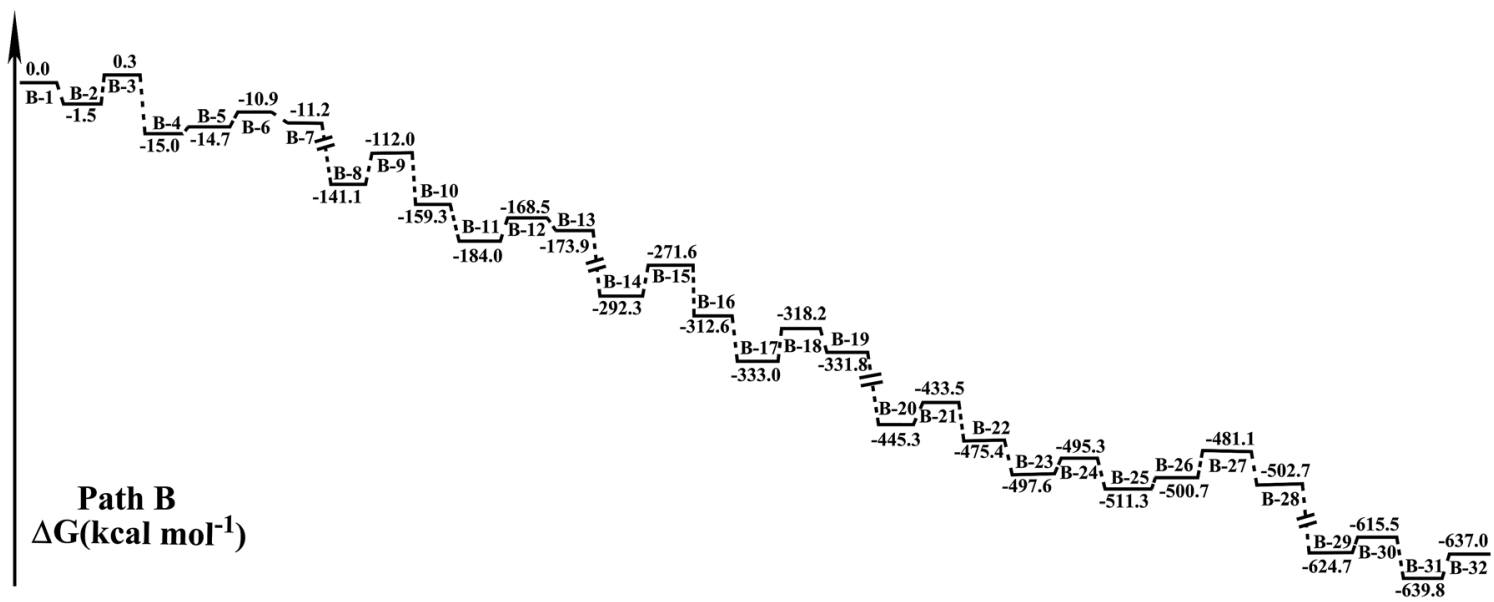

Fig. 4 Schematic energy diagram for potential energy surface of the preferential dinitration on methylene group of MDP in the gas phase predicted via B3LYP-D3/6-311++G(3df,3pd)//B3LYP/6-311G(d,p). The systems with different species are numbered/denoted from "B-1" to "B$32 "$. The correspondence of the serial number and the systems is listed in Table 1.

abstracted, and Ca-IM4 is obtained. Next, C4 in Ca-IM5 is attacked by $\mathrm{NO}_{2}{ }^{+}\left(\mathrm{Ca}-\mathrm{IM} 5 \rightarrow\right.$ Ca-IM6, $\Delta G^{\neq}=28.8 \mathrm{kcal} \mathrm{mol}^{-1}$ ), after which the second $-\mathrm{NO}_{2}$ is introduced. Subsequently, the introduction of the third $-\mathrm{NO}_{2}$ may either follow path $\mathrm{Ca} 1$, which includes two successive steps as the $\mathrm{H}$-abstracting (Ca1IM7 $\rightarrow$ Ca1-IM8, $\Delta G^{\neq}=13.0 \mathrm{kcal} \mathrm{mol}^{-1}$ ) and $\mathrm{NO}_{2}{ }^{+}$attacking (Ca1-IM9 $\rightarrow$ Ca1-IM10, $\Delta G^{\neq}=20.3 \mathrm{kcal} \mathrm{mol}^{-1}$ ), or follow path $\mathrm{Ca} 2$, which includes three successive steps as the H-transferring $\left(\mathrm{Ca} 2-\mathrm{IM} 7 \rightarrow \mathrm{Ca} 2-\mathrm{IM} 8, \Delta G^{\neq}=2.5 \mathrm{kcal} \mathrm{mol}^{-1}\right.$ ), $\mathrm{NO}_{2}^{+}$attacking (Ca2-IM9 $\rightarrow$ Ca2-IM10, $\Delta G^{\neq}=22.5 \mathrm{kcal} \mathrm{mol}^{-1}$ ), and $\mathrm{H}$ abstracting (Ca2-IM11 $\rightarrow$ Ca2-IM12, $\Delta G^{\neq}=5.8 \mathrm{kcal} \mathrm{mol}^{-1}$ ). Finally, the introduction of the last $-\mathrm{NO}_{2}$ may either follow path Ca1, which is identical to that in path B (B-IM15 $\rightarrow$ B-IM20), or follow path $\mathrm{Ca} 2$, which is identical to that in path A (A-IM15 $\rightarrow$ A-IM18).

Path $C b$. The introduction of the first $-\mathrm{NO}_{2}$ to $\mathrm{C} 4$ in this path is identical to that in path B (B-IM1 $\rightarrow$ B-IM6, Fig. 3), followed by Cb-IM1 (Fig. 5) forms. Next, the second $-\mathrm{NO}_{2}$ may be introduced to $\mathrm{C} 10$, resulting in the formation of $\mathrm{Cb}$-IM4. Since $\mathrm{Cb}$ IM4 is exactly the complex of Ca-IM6 with $\mathrm{H}_{2} \mathrm{SO}_{4}$, the subsequent nitration process in path $\mathrm{Cb}$ is actually identical to that in path $\mathrm{Ca}$. In view of this, the pathway similar to path $\mathrm{Ca} 1$ in the introduction of the last two $-\mathrm{NO}_{2}$ is denoted as path $\mathrm{Cb} 1$, and the pathway similar to path $\mathrm{Ca} 2$ is denoted as path $\mathrm{Cb} 2$.

In this way the possible pathways (paths A to $\mathrm{C}$ ) in the $\mathrm{C}$ nitration of MDP with $\mathrm{NO}_{2}^{+}$to form N-MP have been systematically demonstrated. Since four nitro groups are prerequisitly needed to be introduced during the formation of N-MP, the impacts of the introduction order of nitro groups on nitration of MDP should be discerned.

3.1.4 Impacts of the introduction order on nitration. While because the $\Delta G^{\neq}$in the most $\mathrm{NO}_{2}{ }^{+}$attacking steps in path $\mathrm{A}$, path $\mathrm{B}$ or path $\mathrm{C}$ is much higher than that in either $\mathrm{H}$ transferring or $\mathrm{H}$-abstracting, the $\mathrm{NO}_{2}{ }^{+}$attacking step may be the rate-determining step in the nitration of MDP with $\mathrm{NO}_{2}{ }^{+}$. Such $\mathrm{NO}_{2}{ }^{+}$attacking step is thus selected as the model, through which the impacts of the nitration order on the nitration of
MDP is investigated. The $\Delta G^{\neq}$in every $\mathrm{NO}_{2}{ }^{+}$attacking step in path $\mathrm{A}$, path $\mathrm{B}$ and (the four sub-pathways of) path $\mathrm{C}$ in the gas phase is shown in Fig. 7.

As shown in Fig. 7, firstly, it is clear that path A must be more likely to occur, indicating that the C10 in MDP may be preferentially dinitrated. Secondly, it is found that the step (3) in every path may be the rate-determining step during the nitration of MDP. Thirdly, the $\Delta G^{\neq}$of step (2) is found to be very close in paths A to C, so does step (4), indicating that the steps (2) and (4) may be little affected by the nitration order. Additionally, the $\Delta G^{\neq}$of step (1) is found to increase in step with the increase of the number of nitro group on C4 in MDP. It is suggested that the $\mathrm{NO}_{2}{ }^{+}$attacking may be dynamically affected by the introduction of $-\mathrm{NO}_{2}$ and the resulted fluctuation of the charge distribution in the corresponding pre-intermediates.

To discern the reason why path A is the most favorable way among the possible paths, the rate-determining step (3) in paths $\mathrm{A}$ to $\mathrm{C}$ is further investigated, and the atomic charge of every corresponding pre-intermediate is calculated via B3LYP/6$311 \mathrm{G}(\mathrm{d}, \mathrm{p})$. The calculated atomic charges (Mulliken, ${ }^{\mathbf{4 0}} \mathrm{NPA},{ }^{\mathbf{4 3 , 4 4}}$ CHELPG $^{45}$ and Hirshfeld ${ }^{46}$ ) of the pre-intermediates in the step (3) in paths A to $\mathrm{C}$ are shown in Tables 2 and $\mathrm{S} 2, \uparrow$ in which the distance between the pre-reactive atoms in every path is also listed.

We supposed that a stronger attraction between C4 and N16, along with a weaker attraction between $\mathrm{O} 8$ and N16, may contribute to an easier attacking of $\mathrm{NO}_{2}{ }^{+}$to $\mathrm{C} 4$, and a lower $\Delta G^{\neq}$ in the step (3). Such attraction is believed to be dependent on both the quantity of electricity $(Q)$ and the distance $(r)$ between the two atoms. As is clearly seen in Table 2, for the Mulliken atomic charge (the first three rows), C4 in A-IM13 (path A) is more negative than that of either B-IM5 or Ca-IM5, and N16 in the former is more positive than that in the latter two. Simultaneously, the distance between atoms C4 and N16 in A-IM13 is the shortest among the pre-intermediates. Thus it is inferred that the attraction between atoms C4 and N16 in A-IM13 may be stronger than that in B-IM5 or Ca-IM5. However, it is difficult to 

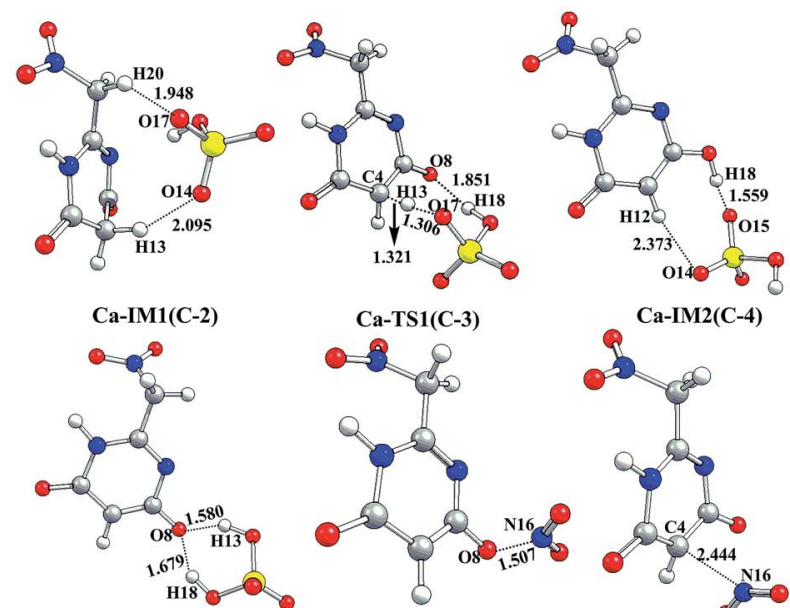

Ca-TS1(C-3)
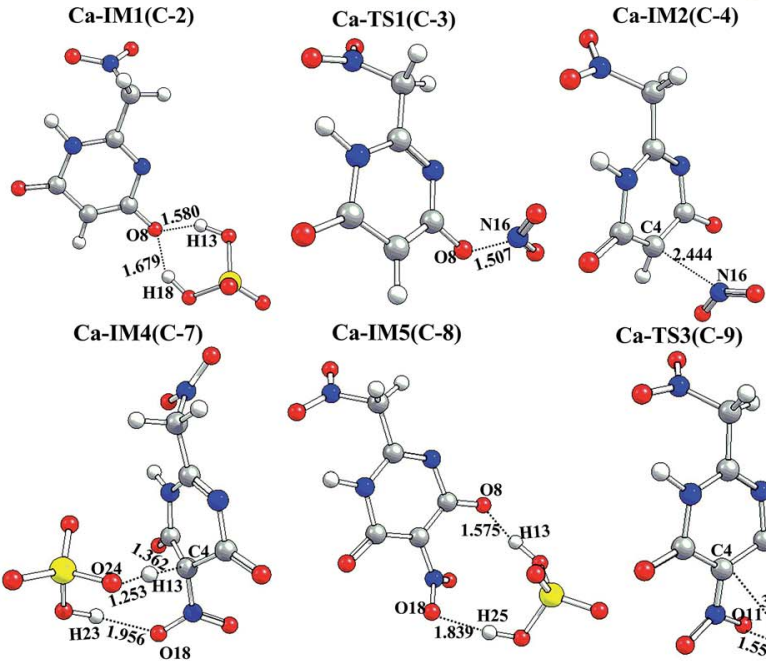

Ca1-TS4(C-12)
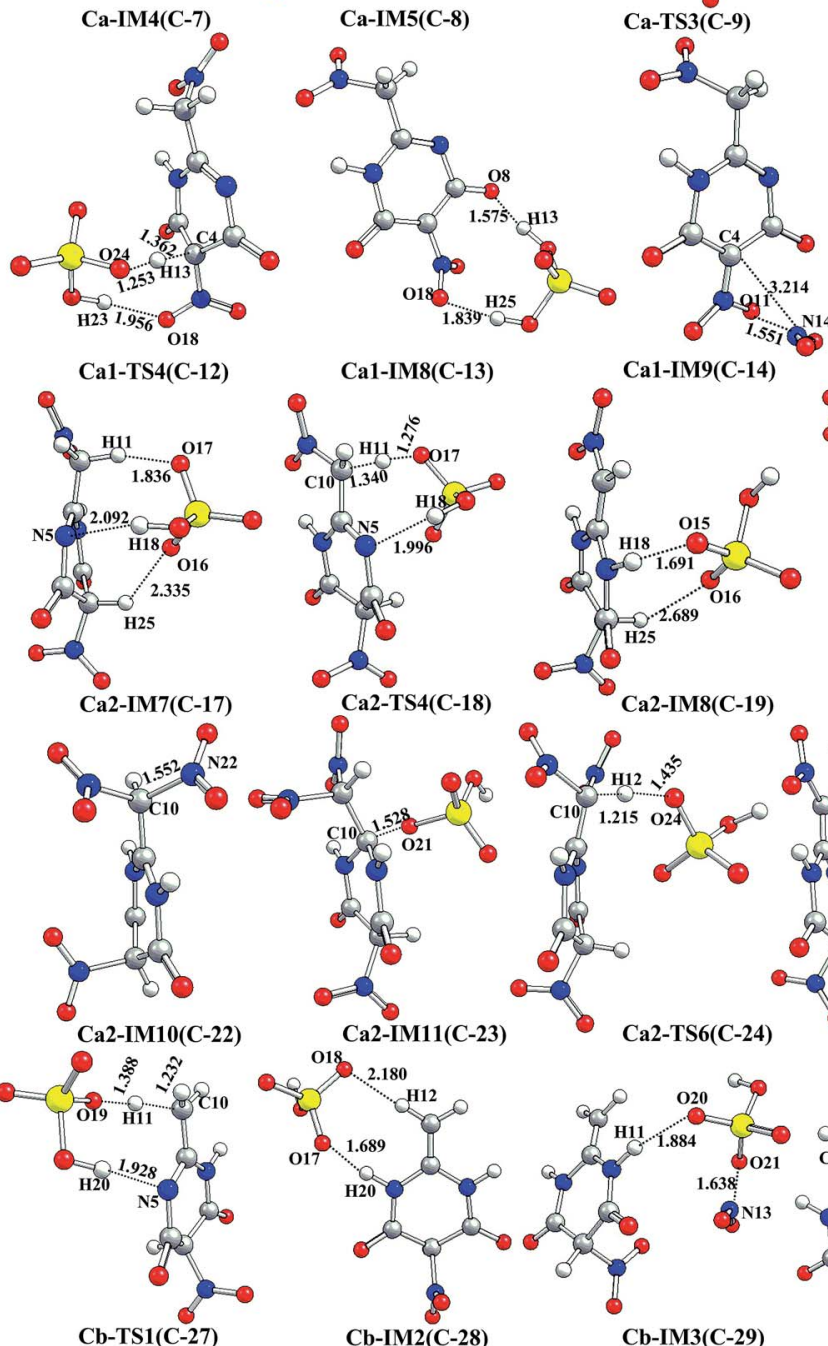

Ca2-IM8(C-19)
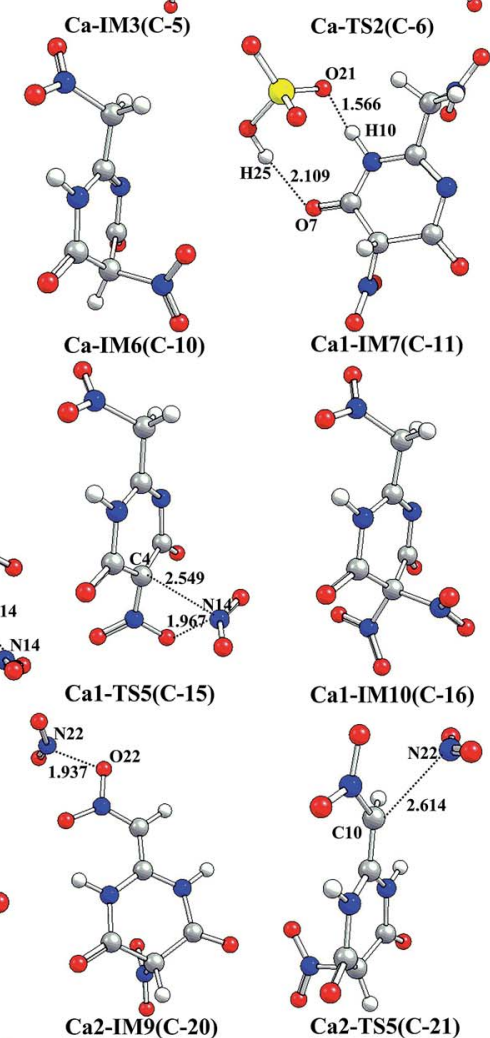

Ca1-IM10(C-16)
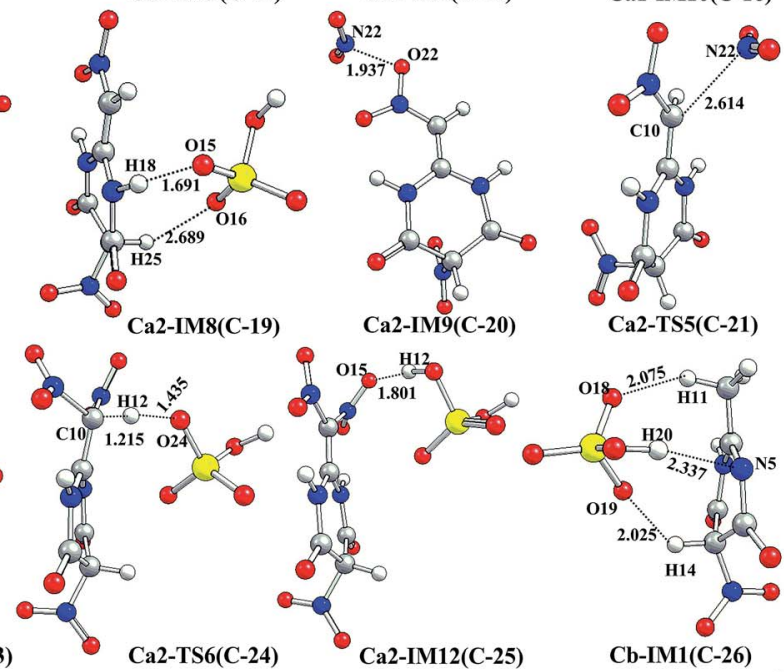

Ca2-IM11(C-23)
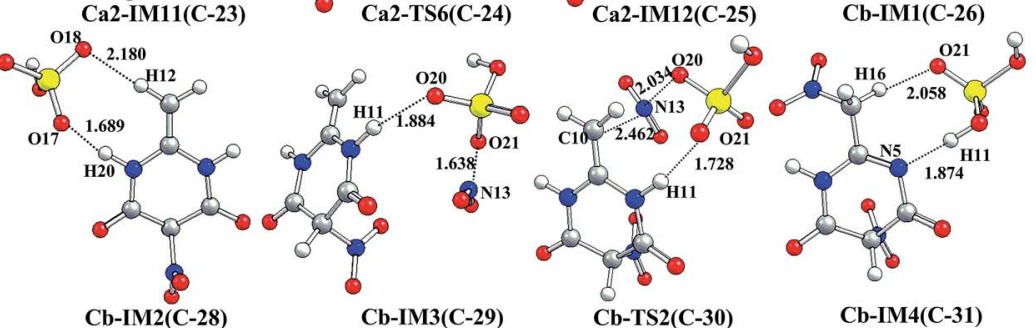

Cb-IM4(C-31)

Fig. 5 Optimized geometries of species in the crossed nitration on methyl and methylene group of MDP calculated via B3LYP/6-311G(d,p) (bond lengths are in angstrom). The serial number (in parentheses) represents the system of corresponding species listed in Table 1.

directly and qualitatively compare/evaluate the attraction between atoms $\mathrm{O} 8$ and $\mathrm{N} 16$ among the three pre-intermediates. Since though the distance between atoms 08 and N16 in A-IM13 is the longest (which may contribute to a weaker attraction), the $Q$ in the two atoms in A-IM13 is the biggest among the three pre- intermediates (which may promote a stronger attraction). Thus the impacts of both the $Q$ and $r$ should be synergistically considered. Here, the Coulomb's law is intentionally employed, through which the attraction between atoms (C4 and N16 versus $\mathrm{O} 8$ and N16) is evaluated. 


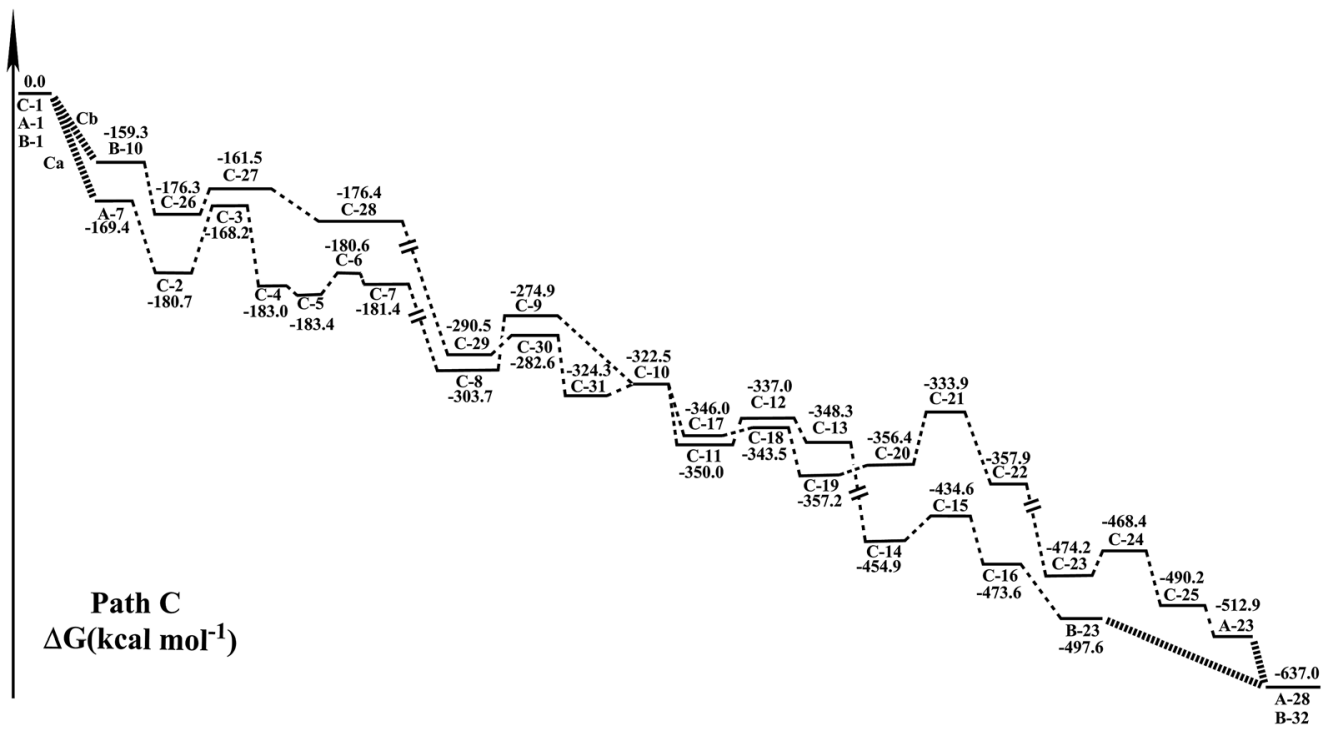

Fig. 6 Schematic energy diagram for potential energy surface of the crossed nitration on methyl and methylene group of MDP predicted via B3LYP-D3/6-311++G(3df,3pd)//B3LYP/6-311G(d,p). The systems with different species are numbered/denoted from "C-1" to "C-25". The correspondence of the serial number and the systems is listed in Table 1.

The Coulomb attraction was estimated based on the atomic charge obtained via the Mulliken method. The results are listed in Table 2 . As is clearly seen in Table 2, among the three pre-intermediates listed, the Coulomb attraction between atoms $\mathrm{C} 4$ and N16 in A-IM13 is the strongest. Meanwhile, the Coulomb attraction between atoms 08 and N16 in A-IM13 is the weakest (as what is expected). Such two

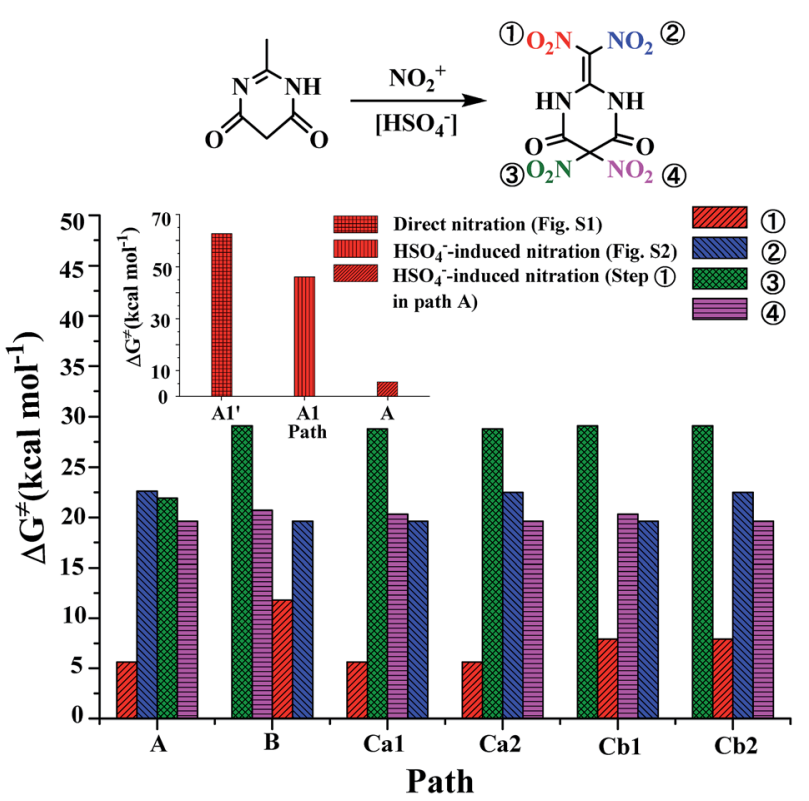

Fig. 7 The activation free energy $\left(\Delta G^{\neq}\right)$in the four nitronium attacking steps (1) to (4) in path A, path B and (the four sub-pathways of) path $C$ in the gas phase predicted via B3LYP-D3/6-311++G(3df,3pd)//B3LYP/ $6-311 G(d, p)$. The insert shows the $\Delta G^{\neq}$in the first nitronium attacking in the paths of preferential dinitration on methyl group with/without the induction of $\mathrm{HSO}_{4}{ }^{-}$. factors may contribute to an easier attacking of $\mathrm{NO}_{2}{ }^{+}$to $\mathrm{C} 4$ in A-IM13, and result in a lower $\Delta G^{\neq}$in the rate-determining step (3). For example, the $\Delta G^{\neq}$in step (3) in path $\mathrm{A}$ is 20.9 kcal mol ${ }^{-1}$, which is approximately $8 \mathrm{kcal} \mathrm{mol}^{-1}$ lower than that in paths $\mathrm{B}$ and $\mathrm{C}$.

The Coulomb attraction was also calculated using the atomic charge from the NPA and CHELPG methods (shown in Table 2). As is seen in Table 2, the Coulomb attraction derived from either NPA or CHELPG method is the strongest between atoms C4 and N16 in A-IM13, and is the weakest between atoms O8 and N16 in A-IM13. Fortunately, such results are in very good agreement with what were obtained from the Mulliken method, indicating that the path A is more likely to occur.

However, as is seen in Table $\mathrm{S} 2, \uparrow$ the Coulomb attraction between atoms C4 and N16 in A-IM13 obtained via Hirshfeld method is not the strongest. Such result is not in accordance with what obtained from Mulliken, NPA or CHELPG method. It seems that other theoretical function besides the Coulomb attraction model should be introduced to discern whether path A is the most favorable nitration way. Here, the Hirshfeld charge is used to construct the condensed Fukui function $(f)$ as well as condensed dual descriptor $(\Delta f)$ according to the method presented by Fuentealba. ${ }^{47}$ The calculated $f$ and $\Delta f$ of the corresponding atoms are listed in Table S3.†

As shown in Table $\mathrm{S} 3, \dagger$ the $f^{-}(r)$ of $\mathrm{C} 4$ in A-IM1 is bigger than that in B-IM15 and Ca-IM5. Meanwhile, the $\Delta f$ of C4 in A-IM13 is found to be more negative than that in B-IM15 and Ca-IM5. Based on the publication, ${ }^{47}$ such results indicate that $\mathrm{C} 4$ in $\mathrm{A}$ IM13 is the most favorable sites to be attacked by $\mathrm{NO}_{2}{ }^{+}$. Hence path A must be the most likely nitration way, which is also in accordance with what were obtained from the Mulliken method. It is clear that the introduction order of $-\mathrm{NO}_{2}$ and the resulted fluctuation of charge distribution in the preintermediates do distinctly impact on the nitration of MDP. 
Table 2 The atomic charge of the atoms and the Coulomb attraction between the atoms of the pre-intermediates in the step (3) in paths A to C in the gas phase

\begin{tabular}{|c|c|c|c|c|c|c|c|c|}
\hline \multirow[b]{2}{*}{ Methods } & \multirow[b]{2}{*}{ Species } & \multicolumn{3}{|l|}{$Q / \mathrm{e}^{a}$} & \multicolumn{2}{|l|}{$r / \mathrm{m}^{b}$} & \multicolumn{2}{|l|}{$F / \mathrm{N}^{c}$} \\
\hline & & $\mathrm{C} 4$ & N16 & 08 & C4-N16 & O8-N16 & C4-N16 & O8-N16 \\
\hline \multirow{2}{*}{ Mulliken } & B-IM15 & -0.207 & 0.435 & -0.290 & $3.477 \times 10^{-10}$ & $1.498 \times 10^{-10}$ & $1.721 \times 10^{-10}$ & $1.299 \times 10^{-9}$ \\
\hline & Ca-IM5 & -0.202 & 0.436 & -0.291 & $3.475 \times 10^{-10}$ & $1.507 \times 10^{-10}$ & $1.685 \times 10^{-10}$ & $1.291 \times 10^{-9}$ \\
\hline NPA & A-IM13 & -0.326 & 0.732 & -0.482 & $3.325 \times 10^{-10}$ & $1.594 \times 10^{-10}$ & $4.986 \times 10^{-10}$ & $3.207 \times 10^{-8}$ \\
\hline \multirow[t]{3}{*}{ CHELPG } & A-IM13 & -0.574 & 0.850 & -0.483 & $3.325 \times 10^{-10}$ & $1.594 \times 10^{-10}$ & $1.019 \times 10^{-9}$ & $3.732 \times 10^{-8}$ \\
\hline & B-IM15 & -0.617 & 0.861 & -0.445 & $3.477 \times 10^{-10}$ & $1.498 \times 10^{-10}$ & $1.014 \times 10^{-9}$ & $3.944 \times 10^{-8}$ \\
\hline & Ca-IM5 & -0.607 & 0.846 & -0.436 & $3.475 \times 10^{-10}$ & $1.507 \times 10^{-10}$ & $9.822 \times 10^{-10}$ & $3.751 \times 10^{-8}$ \\
\hline
\end{tabular}

${ }^{a} Q$, the atomic charge of the pre-intermediates in the step (3) in paths A to C for the nitration of MDP with $\mathrm{NO}_{2}{ }^{+}$calculated via $\mathrm{B} 3 \mathrm{LYP} / 6-311 \mathrm{G}(\mathrm{d}, \mathrm{p})$. To calculate the Coulomb force, the charge unit of e should be transformed to Coulomb (C) with a relationship as: $1 \mathrm{e}=1.602 \times 10^{-19} \mathrm{C} .{ }^{b} r$, the distance between atoms C4 and N16 or atoms O8 and N16 is calculated via B3LYP/6-311G(d,p). ${ }^{c} F$, the Coulomb attraction between atoms C4 and $\mathrm{N} 16$ or atoms $\mathrm{O} 8$ and N16 is calculated by Coulomb's law $\left(F=-k Q_{1} Q_{2} / r^{2}\right)$, where the constant $k$ is $9.0 \times 10^{9} \mathrm{~N} \mathrm{~m}^{2} \mathrm{C}^{-2}$ if other variables take their standard international units.

While the impacts of the introduction order of $-\mathrm{NO}_{2}$ seem not so significant or dominant to promote the nitration if that of the $\mathrm{HSO}_{4}{ }^{-}$induction/enhancement are compared. The first $\mathrm{NO}_{2}{ }^{+}$attacking step in path $\mathrm{A}$ is taken as an example (shown in Fig. 7 (insert)). As shown in Fig. 7, when MDP is directly nitrated/attacked by $\mathrm{NO}_{2}{ }^{+}$(without any assistance of $\mathrm{HSO}_{4}{ }^{-}$) (Fig. S1 $\dagger)$, the $\Delta G^{\neq}\left(62.6 \mathrm{kcal} \mathrm{mol}^{-1}\right)$ is much higher than that in the $\mathrm{HSO}_{4}{ }^{-}$-induced nitration of $\mathrm{MDP}\left(46.1 \mathrm{kcal} \mathrm{mol}^{-1}\right)$, in which the $\mathrm{HSO}_{4}{ }^{-}$-induced $\mathrm{H}$-transferring is not considered (Fig. S2 $\dagger$ ). However, when the $\mathrm{HSO}_{4}{ }^{-}$-induced $\mathrm{H}$-transferring and $\mathrm{H}$-abstracting are synergistically considered, the $\Delta G^{\neq}$in the $\mathrm{NO}_{2}{ }^{+}$attacking step dramatically decreases to merely 5.6 kcal $\mathrm{mol}^{-1}$ (step (1) in path A Fig. 2). Therefore, we strongly suggest that such $\mathrm{HSO}_{4}{ }^{-}$-induced nitration of MDP must be the most favorable way in the $\mathrm{NO}_{2}{ }^{+}$attacking, and should be preferentially considered in this nitration system. We firmly believe that it is the incredible induction/enhancement of $\mathrm{HSO}_{4}{ }^{-}$that effectively promotes/catalyzes the nitration of MDP, and dramatically decreases the $\Delta G^{\neq}$of the titled nitration system.

\subsection{Solvation effect on the nitration of MDP}

Formamide as well as dimethylsulfoxide has been chosen as the model solvent to simulate the bulk solvent effects in the nitration of benzene with mixed acid via CPCM method..$^{25}$ In the present work, the model solvents along with the CPCM method were also introduced and used to evaluate the solvent effects in the rate-determining step in paths A to $\mathrm{C}$. The optimized geometries of the relevant species, and the corresponding energies ( $G$ and $\Delta G^{\neq}$) in the gas (g), formamide (f) and dimethylsulfoxide (d) phases are shown in Fig. S7 and Table S4. $\dagger$

As shown in Fig. S7 and Table $\mathrm{S} 4, \uparrow$ it is clear that though the energies of the relevant species for the rate-determining steps in paths A-C differ distinctly between the gas phase and the solvent phase (formamide or dimethylsulfoxide), the obtained optimized geometries of the relevant species and the $\Delta G^{\neq}$in every rate-determining step are quite analogous. It is indicated that the solvent effect in the nitration of MDP in nitric-sulfuric acids system may be inapparent or at least considerably weak to be omitted. We thus believed the presented mechanism for the titled nitration in the gas phase may be reliable and reasonable.

\section{Conclusions}

The $\mathrm{HSO}_{4}{ }^{-}$induced nitration mechanism of MDP with $\mathrm{NO}_{2}{ }^{+}$to form N-MP is systematically investigated via B3LYP/6-311G(d,p) method. The possible nitration pathways, including the preferential dinitration on methyl group (paths $\mathrm{A}$ and $\mathrm{A}^{\prime}$ ), the preferential dinitration on methylene group (path $B$ ), and the crossed nitration (path $\mathrm{C}$ ), are excavated and illustrated, respectively.

A unique induction/enhancement of the co-existed $\mathrm{HSO}_{4}{ }^{-}$to the nitration is proposed and discerned. It is clearly indicated that $\mathrm{HSO}_{4}{ }^{-}$-induced nitration of MDP with $\mathrm{NO}_{2}{ }^{+}$must be the most favorable way as compared with the nitration without the assistance of $\mathrm{HSO}_{4}{ }^{-}$. It is strongly suggested that the incredible induction/enhancement of $\mathrm{HSO}_{4}{ }^{-}$may effectively promote/ catalyze the nitration of MDP with $\mathrm{NO}_{2}{ }^{+}$, including not only the $\mathrm{NO}_{2}{ }^{+}$attacking, but the $\mathrm{H}$-transferring and $\mathrm{H}$-abstracting as well, and thus dramatically decrease the $\Delta G^{\neq}$of the nitration system.

The impact of the introduction order of $-\mathrm{NO}_{2}$ on the nitration is systematically demonstrated. Based on the $\Delta G^{\neq}$of the rate-determining step, it is found that path A must be more likely to occur, indicating that $\mathrm{C} 10$ in MDP may be preferentially dinitrated in the presence of $\mathrm{HSO}_{4}{ }^{-}$. Moreover, it is suggested that the $\mathrm{NO}_{2}{ }^{+}$attacking may be dynamically affected by the introduced $-\mathrm{NO}_{2}$ and the resulted fluctuation of the charge distribution in the pre-intermediates. The atomic charge along with the Coulomb attractions between the corresponding atoms of the pre-intermediates is intentionally calculated, through which the reason why path A is the most favorable nitration way among all the possible paths is verified and discerned. 
The solvent effect in the nitration of MDP in nitric-sulfuric acids seems to be inapparent. Reasonable mechanism may be proposed in the gas phase without considering the solvent effect.

We believe that the proposed $\mathrm{HSO}_{4}{ }^{-}$-induction, the fluctuation of the charge distribution and the resulted favorable nitration order may also fit for the similar nitration systems, such as the nitration of aromatics and other heterocyclic compounds. It is optimistically expected that the present study may provide a theoretical basis to the research and engineering tests of the preparation of FOX-7, and may strongly promote the exploration of other nitro energetic materials.

\section{Acknowledgements}

The authors gratefully acknowledge the financial support from the National Natural Science Foundation of China (21306111, 21327011), the Program for Changjiang Scholars and Innovative Research Team in University (IRT_14R33), the Shaanxi Innovative Team of Key Science and Technology (2013KCT-17), the Natural Science Research Program of Shaanxi Province (2014JM2034), and the Fundamental Research Funds for the Central Universities (GK201401001, GK201603103).

\section{Notes and references}

1 N. V. Latypov, J. Bergman, A. Langlet, U. Wellmar and U. Bemm, Tetrahedron, 1998, 54, 11525-11536.

2 N. V. Latypov, U. Wellmar and A. Langlet, US Pat., No. 6340780 B1, 2002.

3 H. Q. Cai, Y. J. Shu, H. Huang, B. B. Cheng and J. S. Li, J. Org. Chem., 2004, 69, 4369-4374.

4 H. Q. Cai, Y. J. Shu, W. F. Yu, J. S. Li and B. B. Cheng, Acta Chim. Sin., 2004, 62, 295-301.

5 A. K. Mandal, U. Thanigaivelan, R. K. Pandey, S. Asthana, R. B. Khomane and B. D. Kulkarni, Org. Process Res. Dev., 2012, 16, 1711-1716.

6 N. V. Latypov, M. Johansson, E. Holmgren, E. V. Sizova, V. V. Sizov and A. J. Bellany, Org. Process Res. Dev., 2007, 11, 56-59.

7 R. Gilardi, CCCD 127539, Cambridge Structural Database, Cambridge Crystallographic Data Center, Cambridge, U. K., 1999.

8 D. C. Sorescu, J. A. Boatz and D. L. Thopmson, J. Phys. Chem. A, 2001, 105, 5010-5021.

9 D. E. Taylor, F. Rob, B. M. Rice, R. Podeszwa and K. Szalewicz, Phys. Chem. Chem. Phys., 2011, 13, 1662916636.

10 (a) F. J. Zerilli and M. M. Kuklja, J. Phys. Chem. A, 2006, 110, 5173-5179; (b) F. J. Zerilli and M. M. Kuklja, J. Phys. Chem. A, 2007, 111, 1721-1725.

11 (a) B. B. Averkiev, Z. A. Dreger and S. Chaudhuri, J. Phys. Chem. A, 2014, 118, 10002-10010; (b) S. Hunter, P. L. Coster, A. J. Davidson, D. I. A. Millar, S. F. Parker, W. G. Marshall, R. I. Smith, C. A. Morrison and C. R. Pulham, J. Phys. Chem. C, 2015, 119, 2322-2334.
12 K. Z. Xu, J. R. Song, F. Q. Zhao, Z. H. Cao, H. X. Ma, R. Z. Hu, H. X. Gao and J. Huang, Acta Chim. Sin., 2007, 65, 2827-2831. 13 G. Majano, S. Mintova, T. Bein and T. M. Klapötke, J. Phys. Chem. C, 2007, 111, 6694-6699.

14 Q. Sun, Y. Zhang, K. Z. Xu, Z. Y. Ren, J. R. Song and F. Q. Zhao, J. Chem. Eng. Data, 2015, 60, 2057-2061.

15 J. Evers, T. M. Klapötke, P. Mayer, G. Oehlinger and J. Welch, Inorg. Chem., 2006, 45, 4996-5007.

16 X. Fang and W. G. McLuckie, J. Hazard. Mater., 2015, 285, 375-382.

17 W. A. Trzciński, S. Cudzilo, Z. Chylek and L. Szymańczyk, J. Hazard. Mater., 2008, 157, 605-612.

18 (a) X. Z. Fan, J. Z. Li and Z. R. Liu, J. Phys. Chem. A, 2007, 111, 13291-13295; (b) A. Gindulyté, L. Massa, L. Huang and J. Karle, J. Phys. Chem. A, 1999, 103, 11045-11051; (c) R. S. Bootha and L. J. Butlerb, J. Chem. Phys., 2014, 141, 134315/1-134315/9; (d) V. G. Kiselev and N. P. Gritsan, J. Phys. Chem. A, 2014, 118, 8002-8008; (e) Y. Liu, F. Li and H. Sun, Theor. Chem. Acc., 2014, 133, 1567/1-1567/11; (f) B. Yuan, Z. J. Yu and E. R. Bernstein, J. Chem. Phys., 2014, 140, 074708/1-074708/9; (g) H. X. Gao, F. Q. Zhao, R. Z. Hu, Q. N. Pan, B. Z. Wang, X. W. Yang, Y. Gao, S. L. Gao and Q. Z. Shi, Chin. J. Chem., 2006, 24, 177-181.

19 G. Hervé, G. Jacob and N. Latypov, Tetrahedron, 2007, 63, 953-959.

20 H. X. Gao and J. M. Shreeve, Angew. Chem., Int. Ed., 2015, 54, 6335-6338.

21 (a) E. V. Sizova, V. V. Sizov and D. I. V. Tselinskii, Russ. J. Org. Chem., 2007, 43, 1232-1237; (b) T. T. Vo and J. M. Shreeve, J. Mater. Chem. A, 2015, 3, 8756-8763.

22 E. K. Kim, T. M. Bockman and J. K. Kochi, J. Am. Chem. Soc., 1993, 115, 3091-3104.

23 P. M. Esteves, J. W. D. M. Carneiro, S. P. Cardoso, A. G. H. Barbosa, K. K. Laali, G. Rasul, G. K. Surya Prakash and G. A. Olah, J. Am. Chem. Soc., 2003, 125, 4836-4849.

24 V. D. Parker, T. Kar and D. Bethell, J. Org. Chem., 2013, 78, 9522-9525.

25 G. Koleva, B. Galabov, B. Hadjieva, H. F. Schaefer III and P. V. R. Schleyer, Angew. Chem., Int. Ed., 2015, 54, 14123-14127.

26 Z. H. Zhen and Y. R. Mo, J. Chem. Theory Comput., 2013, 9, 4428-4435.

27 L. T. Chen, H. M. Xiao, J. J. Xiao and X. D. Gong, J. Phys. Chem. A, 2003, 107, 11440-11444.

28 L. T. Chen, H. M. Xiao and J. J. Xiao, J. Phys. Org. Chem., 2005, 18, 62-68.

29 L. X. Jin, L. Wang, C. Y. Zhang, W. L. wang, S. T. Min and D. D. Hu, Phys. Chem. Chem. Phys., 2014, 16, 16264-16267.

30 K. Wang, J. G. Chen, B. Z. Wang, F. Y. Liu, Z. T. Liu, Z. W. Liu, W. L. Wang, J. Q. Jiang, Z. P. Hao and J. Lu, RSC Adv., 2015, 5, 25183-25191.

31 K. Wang, J. G. Chen, B. Z. Wang, J. Lu, W. L. Wang, F. Y. Liu, C. Zhou, P. Lian, Z. W. Liu and Z. T. Liu, Chem. J. Chin. Univ., 2015, 36, 531-538.

32 The hydrolysis of N-MP to form FOX-7 will be presented elsewhere.

33 N. C. Marziano, A. Tomasin, C. Tortato and J. S. Zaldivar, J. Chem. Soc., Perkin Trans. 2, 1998, 2, 1973-1982. 
34 M. J. Frisch, G. W. Trucks, H. B. Schlegel, G. E. Scuseria, M. A. Robb, J. R. Cheeseman, G. Scalmani, V. Barone, B. Mennucci, G. A. Petersson, H. Nakatsuji, M. Caricato, X. Li, H. P. Hratchian, A. F. Izmaylov, J. Bloino, G. Zheng, J. L. Sonnenberg, M. Hada, M. Ehara, K. Toyota, R. Fukuda, J. Hasegawa, M. Ishida, T. Nakajima, Y. Honda, O. Kitao, H. Nakai, T. Vreven, J. A. Montgomery Jr, J. E. Peralta, F. Ogliaro, M. Bearpark, J. J. Heyd, E. Brothers, K. N. Kudin, V. N. Staroverov, T. Keith, R. Kobayashi, J. Normand, K. Raghavachari, A. Rendell, J. C. Burant, S. S. Iyengar, J. Tomasi, M. Cossi, N. Rega, J. M. Millam, M. Klene, J. E. Knox, J. B. Cross, V. Bakken, C. Adamo, J. Jaramillo, R. Gomperts, R. E. Stratmann, O. Yazyev, A. J. Austin, R. Cammi, C. Pomelli, J. W. Ochterski, R. L. Martin, K. Morokuma, V. G. Zakrzewski, G. A. Voth, P. Salvador, J. J. Dannenberg, S. Dapprich, A. D. Daniels, O. Farkas, J. B. Foresman, J. V. Ortiz, J. Cioslowski and D. J. Fox, Gaussian 09, Revision B.01, Gaussian, Inc, Wallingford, CT, 2010.

35 C. Lee, W. T. Yang and R. G. Parr, Phys. Rev. B: Condens. Matter Mater. Phys., 1988, 37, 785-789.

36 A. D. McLean and G. S. Chandler, J. Chem. Phys., 1980, 72, 5639-5648.

37 C. Gonzales and H. B. Schlegel, J. Chem. Phys., 1989, 90, 2154-2161.
38 S. Grimme, J. Antony, S. Ehrlich and H. Krieg, J. Chem. Phys., 2010, 132, 154104-154119.

39 S. Grimme, S. Ehrlich and L. Goerigk, J. Comput. Chem., 2011, 32, 1456-1465.

40 R. S. Mulliken, J. Chem. Phys., 1955, 23, 1833-1840.

41 (a) V. Barone and M. Cossi, J. Phys. Chem. A, 1998, 102, 19952001; (b) M. Cossi, N. Rega, G. Scalmani and V. Barone, J. Comput. Chem., 2003, 24, 669-681.

42 (a) F. Cacace, M. Attinà, G. D. Petris and M. Speranza, J. Am. Chem. Soc., 1990, 112, 1014-1018; (b) E. D. Hughes, C. Ingold and R. B. Pearson, J. Chem. Soc., 1958, 4357-4365; (c) E. L. Blackall, E. D. Hughes, C. Ingold and R. B. Pearson, J. Chem. Soc., 1958, 4366-4374; (d) T. J. Lee and J. E. Rice, J. Phys. Chem., 1992, 96, 650-657.

43 A. E. Reed, R. B. Weinstock and F. Weinhold, J. Chem. Phys., 1985, 83, 735-746.

44 A. E. Reed, L. A. Curtiss and F. Weinhold, Chem. Rev., 1988, 88, 899-926.

45 C. M. Breneman and K. B. Wiberg, J. Comput. Chem., 1990, 11, 361-373.

46 F. L. Hirshfeld, Theor. Chim. Acta, 1977, 44, 129-138.

47 P. Fuentealba, E. Florez and W. Tiznado, J. Chem. Theory Comput., 2010, 6, 1470-1478. 